REVIEW ARTICLE

\title{
Host-parasite biology in the real world: the field voles of Kielder
}

\author{
A. K. TURNER ${ }^{1}$, P. M. BELDOMENICO ${ }^{1,2,3}$, K. BOWN $^{1,4}$, S. J. BURTHE ${ }^{1,2,5}$, \\ J. A. JACKSON ${ }^{1,6}, \mathrm{X} . \mathrm{LAMBIN}^{7}$ and M. BEGON ${ }^{1} *$ \\ ${ }^{1}$ Institute of Integrative Biology, University of Liverpool, UK \\ ${ }^{2}$ National Centre for Zoonosis Research, University of Liverpool, UK \\ ${ }^{3}$ Laboratorio de Ecología de Enfermedades, Instituto de Ciencias Veterinarias del Litoral, Universidad Nacional del \\ Litoral-Consejo de Investigaciones Cientificas y Técnicas (UNL-CONICET), Esperanza, Argentina \\ ${ }^{4}$ School of Environment $\mathcal{E}^{\circ}$ Life Sciences, University of Salford, UK \\ ${ }^{5}$ Centre for Ecology $\Xi^{\circ}$ Hydrology, Natural Environmental Research Council, Edinburgh, UK \\ ${ }^{6}$ Institute of Biological, Environmental and Rural Sciences, University of Aberystwyth, UK \\ ${ }^{7}$ School of Biological Sciences, University of Aberdeen, UK
}

(Received 10 October 2013; revised 20 December 2013 and 20 Fanuary 2014; accepted 22 Fanuary 2014; first published online 10 March 2014)

\section{SUMMARY}

Research on the interactions between the field voles (Microtus agrestis) of Kielder Forest and their natural parasites dates back to the 1930s. These early studies were primarily concerned with understanding how parasites shape the characteristic cyclic population dynamics of their hosts. However, since the early 2000s, research on the Kielder field voles has expanded considerably and the system has now been utilized for the study of host-parasite biology across many levels, including genetics, evolutionary ecology, immunology and epidemiology. The Kielder field voles therefore represent one of the most intensely and broadly studied natural host-parasite systems, bridging theoretical and empirical approaches to better understand the biology of infectious disease in the real world. This article synthesizes the body of work published on this system and summarizes some important insights and general messages provided by the integrated and multidisciplinary study of host-parasite interactions in the natural environment.

Key words: field vole, Microtus agrestis, Kielder, host, parasite, infectious disease, dynamics.

\section{INTRODUCTION}

Almost 90 years ago, Charles Elton drew attention to the potential importance of parasites in the dynamics of natural populations (Elton, 1924; Elton et al. 1931). Nonetheless, for many decades in the 20th century, both this and the dynamics of the parasites themselves were Cinderella subjects in ecology, neglected in comparison with their sister interactions, predation and competition. The tide was turning, though, in the 1970 s and early 80 s, and may be said to have done so decisively with the publication of seminal papers by Anderson and May at that time (Anderson and May, 1979; May and Anderson, 1979). However, these papers and many that followed were theory-oriented, and field data with which to confront these theories were then - and remain still - in relatively short supply.

In Liverpool in the 1990s, separate lines of research were being pursued on host-parasite dynamics in laboratory populations of moths (Begon et al.

* Corresponding author. Institute of Integrative Biology, University of Liverpool, Crown Street, Liverpool L69 7ZB, UK. E-mail: mbegon@liv.ac.uk
1996) and the distribution of a zoonotic pathogen, cowpox virus, in natural populations of rodents (Crouch et al. 1995). There were obvious attractions in moving from the laboratory to the field, in looking more deeply into the ecology of cowpox virus, and in re-visiting host-parasite dynamics in rodents, the favoured hosts of Charles Elton (himself a Liverpudlian). Work was initially on bank voles (Myodes glareolus) and wood mice (Apodemus sylvaticus) in woodland habitats on the Wirral peninsula, near Liverpool, where both species exhibited clear annual (autumn) peaks in abundance, but no demonstrable multi-annual patterns and indeed only moderate variation in abundance from year to year (Hazel et al. 2000). Then, from the early 2000s, the focus began to shift to populations of field voles (Microtus agrestis) (Fig. 1) in Kielder Forest on the England-Scotland border, living in grassland habitats and exhibiting multi-annual cycles in their abundance (Lambin et al. 2000). These latter are the focus of this review. However, where related work on bank voles and wood mice sheds light on the Kielder Forest field vole system, this too is described.

Studying hosts with cyclic dynamics offers two particular advantages in the context of host-parasite 


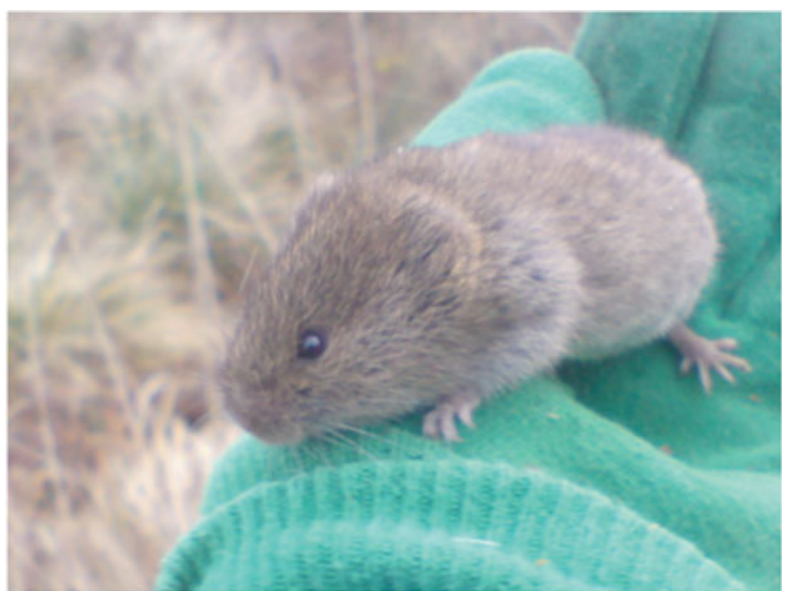

Fig. 1. The field vole, Microtus agrestis.

dynamics in natural populations. First, where the aim is to investigate the role of parasites in driving host dynamics, it is necessary to know what is 'signal' in those dynamics (and hence liable to explanation) and what is simply noise. In cyclic systems there is a clear dominance of signal over noise. Second, many key aspects of the dynamics of the parasites themselves, including those concerned with transmission and host condition, are dependent on host density. In order to have the statistical power to study these effects in a natural population, a system must provide observations across a whole spectrum of densities. Systems with cyclic dynamics are likely to do this and to do so in a predictable way that allows scientific investigation to be planned, as highlighted by the extensive research performed on another cyclic system, the Soay sheep of St Kilda (Clutton-Brock and Pemberton, 2004).

\section{BACKGROUND TO THE SYSTEM}

The Kielder Forest area has a long history of being affected by irruptions of field voles, sometimes of plague proportions (Elton et al. 1935; Elton, 1942). Indeed, some of the first steps in studying the population ecology of disease by researchers in Charles Elton's Bureau of Animal Populations were made on field voles in or near Kielder Forest (Chitty, 1954, 1996). The Liverpool group's move from studying local bank voles and wood mice populations to work on the field voles of Kielder was greatly facilitated by the initiation of a collaboration with Xavier Lambin's group at the University of Aberdeen. Prior to the collaboration, the Aberdeen group had been investigating the processes behind temporal and spatial dynamics of field voles (e.g. Mackinnon et al. 2001), including the role of predators in shaping spatial dynamics (Petty et al. 2000; Sherratt, 2001), and had been utilizing both monitoring and field-experimental approaches (Ergon et al. 2001a,b; Graham and Lambin, 2002).
In addition, a study of raptor dynamics has entailed monitoring field vole abundance since 1983 (Petty, 1992) and thus the spatiotemporal dynamics of field voles in Kielder have been exceptionally well characterized. Data reveal a pattern of multi-annual fluctuation with peak vole densities occurring at a 3-4 year interval, followed by steep population collapses usually taking place in summer during the vole breeding season, and followed by up to a year with little noticeable population growth (Lambin et al. 2000). 'The 'Chitty effect' (Chitty, 1952; Boonstra and Krebs, 1979), whereby adults in the high-density phase of the population cycle exhibit larger average body mass than during the low phase, is apparent in the Kielder field voles, seemingly through prolonged growth periods rather than increased growth rates (Burthe et al. 2010). Within a single grass patch, maximum densities span 5-770 voles ha ${ }^{-1}$ (Burthe et al. 2006), but at a landscape scale the span is 50-220 voles ha ${ }^{-1}$ (Lambin et al. 1998, 2000; Mackinnon et al. 2001). Critically, there is no evidence that voles ever go extinct at any spatial scale in the system. This has implications for the dynamics of species linked to voles, as neither predators nor pathogens are expected to experience extinction-recolonization dynamics in the system.

The population cycles are generally asynchronous among populations across Kielder, although populations situated close together often fluctuate in a synchronous manner (Lambin et al. 1998). Indeed, vole spatial dynamics in Kielder Forest were, at least for a time, spatially organized in travelling waves (Lambin et al. 1998; Bierman et al. 2006). These spatial dynamics, in addition to their intrinsic interest, provide scope for substituting space for time in sampling host populations at a range of densities.

The field voles have 'fast' life histories typical of microtine rodents, with high fecundity (an average litter size of five), a low age at maturation for some seasonal cohorts (as little as 28 days old for springand early summer-born females), and birth intervals by members of overlapping cohorts as short as 21 days during a breeding season. The field vole breeding season, for the most part, coincides with the plant growing season. However, for individuals born in the second half of the breeding season, reproduction is typically delayed until the next spring. There is therefore a strong seasonality to reproduction and the production of cohorts of susceptible individuals. Juveniles and subadults, but also females breeding in the year of birth, have non-defended home ranges, though overwintered females do tend to defend territories (Pusenius and Viitala, 1993). Dispersal is primarily by subadults. Thus there is also a distinct seasonal pattern to the spatial range and the number of individuals with whom individuals make potentially infectious contacts. 
Kielder Forest is intensely managed for timber production. Hence, grassland areas are restricted to roads, unplanted river margins and restock sites where dense grass cover establishes 2-3 years after rotational timber harvesting and persists for 10-12 years after planting. Restock sites are typically 5-25 ha in size and are embedded in a matrix of dense spruce plantation with no grass cover. The field vole is a grass-eating species that therefore relies more than bank voles on well-vegetated areas. The bank vole, common shrew (Sorex araneus) and pygmy shrew (Sorex minutus) share many arthropod disease vectors and some pathogens with field voles and also mostly occupy grassy areas, whereas wood mice use both the forested landscape matrix and the semi-isolated grassland patches.

\section{THE DATASETS}

Many of the Kielder studies used all or part of two datasets, and so the nature and derivation of these are described first in outline. The one used most often was a longitudinal, time series dataset (for full details see, for example, Burthe et al. 2006). Field voles were trapped in four similar-sized clear-cuts, in two areas of the forest approximately $12 \mathrm{~km}$ apart, between May 2001 and March 2007 (Fig. 2). Two sites in the Kielder catchment, Kielder Site (KCS) and Plashett's Jetty (PLJ) are situated $4 \mathrm{~km}$ apart. Two further sites in the adjacent Redesdale Forest catchment, Black Blake Hope (BHP) and Rob's Wood (ROB), are $3.5 \mathrm{~km}$ apart. These four populations are far enough apart, with sufficient forest between them, to be considered as effectively independent replicates. Populations were trapped in 'primary' sessions every $\sim 28$ days from March to November, and every $\sim 56$ days from November to March. Each site had a permanent 0.3 ha livetrapping grid consisting of 100 Ugglan Special Mousetraps (Grahnab, Marieholm, Sweden), in optimal habitat dominated by Deschampsia caespitosa, Agrostis tenuis and Funcus effusus grasses. Traps were set at $5 \mathrm{~m}$ intervals and baited with oats/wheat and carrots. Traps were pre-baited 3 days before each trapping session, set at approximately 18:00 on the first day and checked five times ('secondary sessions') at roughly $12 \mathrm{~h}$ intervals, starting and ending at dawn and dusk, respectively. Mass, sex, body condition and reproductive status (assigned according to the external appearance of reproductive organs) was recorded at the time of first capture in each primary session. Individual animals were identified using subcutaneous microchip transponders (AVID plc, East Sussex, UK) injected into the skin at the back of the neck. Total population size was estimated by capture-recapture methods assuming a closed population, from data within a primary session.

A $20-30 \mu \mathrm{L}$ blood sample was taken from the tail tip of each individual each primary session, usually in the first secondary session in which it was caught. These provided the material for pathogen diagnoses and haematological measurements (see later sections). The presence and (in some cases) the number and identity of ectoparasites were also noted. In addition, the presence of external skin lesions characteristic of late-stage vole tuberculosis (caused by the bacterium Mycobacterium microti, see below) was noted in the field. Hence, in those cases where individuals were recaptured in one or more primary sessions, the time course of infections in individuals and transitions in individual status could be monitored, as well as the profiles of whole populations being followed over time.

The second, cross-sectional dataset was derived from traps set bi-annually in March (spring) and September (autumn) in 27 grass-dominated clear-cut sites (5-12 ha) within the three adjacent catchments of Kielder Forest (for full details see, for example, Telfer et al. 2007a). This design used 'destructive' sampling methods, in which captured voles were euthanized. There were 12 sites located in the Kielder catchment, 10 within the Kershope catchment and 5 sites within the Redesdale catchment (Fig. 2). The minimum and maximum inter-site distances were 0.4 and $36.9 \mathrm{~km}$ respectively. Within each clearcut, small mammals were sampled using the small quadrant design (Myllymaki et al. 1971): a $15 \times 15 \mathrm{~m}$ trapping square was established in good quality field vole habitat and three Ugglan traps were set at each corner. Other procedures were as described for the longitudinal study.

An inherent disadvantage of cross-sectional destructive sampling is that it provides only a snapshot of each host within the dynamics of a host-parasite system; one cannot distinguish causation from mere association, because all measurements are coincident. Nonetheless, a major advantage of such methods is that additional data can be obtained from euthanized individuals (e.g. larger blood volume, organ samples, confirmed reproductive status, etc.).

The dataset used for the immunological work, and also providing data for genetic studies (see later sections), was separate from these (Jackson et al. 2011). It came from repeated trapping at two spatially separate sites from February 2008 to March 2009 and a further two from April 2009 to March 2010, and had both longitudinal and cross-sectional components. Each site contained a live-trapping grid $(\sim 0 \cdot 375 \mathrm{ha})$ of $150(10 \times 15)$ regularly spaced traps (3-5 $\mathrm{m}$ intervals) placed in optimal habitat for the longitudinal study. There were also satellite transects on each (with traps spaced at $\geqslant 5 \mathrm{~m}$ intervals) from which 10 animals per month per site were sampled destructively (to allow a wider range of immunological measurements) for the cross-sectional component of the study. At each site, there were monthly trapping sessions from February/April to November, during which capture-recapture and 


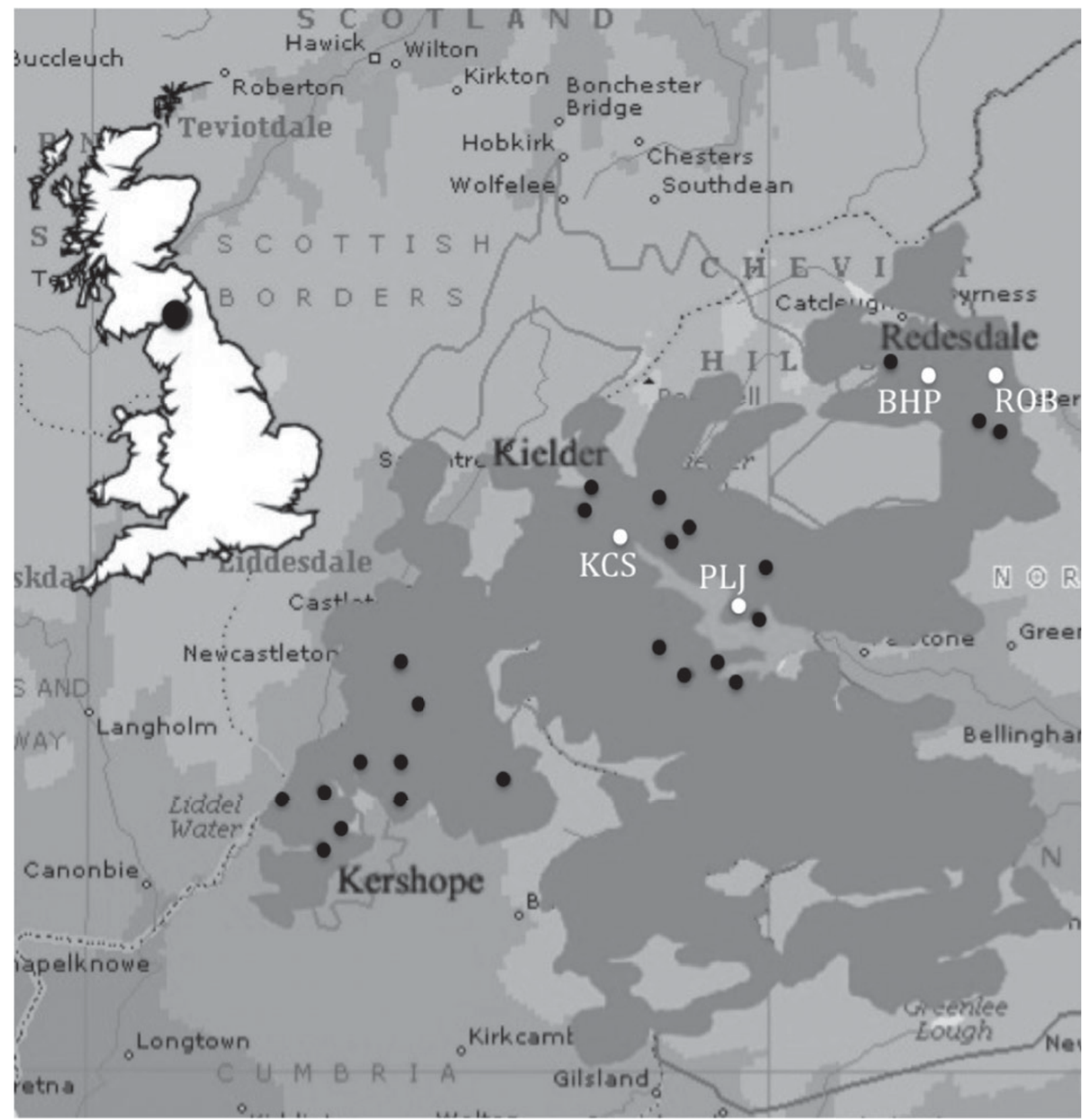

Fig. 2. Map of longitudinal (white, labelled) and cross-sectional (all) sites within Kielder Forest and surrounding area.

destructive samples were taken. Then, in November and again in the following March, larger numbers of animals were destructively sampled both from the transects and from the grid habitats. Other procedures were as described previously.

\section{EPIDEMIOLOGY OF INDIVIDUAL PATHOGENS}

The Kielder field voles are subject to infection by a number of endemic micro- and macroparasite species, of which the microparasite community has been the most extensively studied (Table 1). Many of these species are zoonotic or related to pathogens of medical or veterinary importance and include directly transmitted and vector-borne pathogens, and the ectoparasitic vectors themselves. Here, we provide brief summaries of the background biology and epidemiological patterns displayed by the pathogen species most closely studied in Kielder, followed by more thematic sections drawing together results from ranges of pathogens.

\section{Cowpox virus}

Cowpox is an orthopoxvirus endemic throughout European and western Asian rodent populations (Baxby and Bennett, 1999). Despite its name, cowpox virus rarely infects cattle and is actually most often diagnosed in domestic cats (Cavanagh et al. 2004). The virus is also a zoonosis, although human cases are rare (Baxby et al. 1994). Field voles, bank voles and wood mice appear to be the primary 
reservoir hosts in the UK (Chantrey et al. 1999), with Kielder field voles exhibiting a prevalence of $28-100 \%$, peaking in mid to late summer (Burthe et al. 2006). A summer peak in seropositivity was also observed in the Liverpool populations of bank voles and wood mice, though at lower prevalences (Hazel et al. 2000). Animals infected with the virus develop an antibody response after around 2 weeks and remain infected for approximately 4 weeks (Chantrey et al. 1999).

Further analysis showed that both the number infected with cowpox virus and the prevalence of infection increased with total population size (Begon et al. 2009a). However, whereas previous work in bank voles had suggested a threshold abundance, below which infection was not found (Begon et al. 2003), evidence for such a threshold in field voles was at best equivocal, in spite of the wide range of abundances sampled (Begon et al. 2009a).

Field vole abundance was most strongly correlated with contemporary values of numbers infected and prevalence. However, in the case of the numbers of susceptible hosts, the strongest correlations were with values 1-2 months preceding the values for numbers infected and prevalence. Thus, in transfer function analyses (a statistical technique aimed at identifying drivers of an output - in this case, new infections - in terms of potential inputs), as epidemiological theory would predict, the number of 'susceptibles' (which 'drive' new infections) were much more effective than those of total vole abundance (of which susceptibles are only a component) in predicting future numbers infected. Nonetheless, while monitoring the number of susceptible individuals has most to offer, the results suggest that monitoring overall abundance, which is much more common and more easily achieved, may nonetheless provide valuable insights into the dynamics of infection (Begon et al. 2009a).

The seasonality of cowpox virus dynamics was examined further by Begon et al. (2009b). The timing of seasonal peaks in new infection within the year was related to the multi-annual patterns of abundance displayed by the voles, which in turn was associated with both the number and the rate of recruitment of susceptible hosts. A plentiful and sustained supply of susceptible hosts throughout the summer (March-September), such as occurs in the increase phase in the abundance cycle, gave rise to a steady increase in infected hosts and a peak late in the year - often October or November. However, a meagre supply of susceptible hosts more limited in time, such as occurs in a crash year, was often insufficient to sustain an increase in infected hosts, leading to an early peak, around June, followed by a decline. This was in contrast to more predictable seasonal peaks seen in some human infections (Stone et al. 2007), the lesson being that to understand seasonal disease dynamics in wildlife populations, the dynamics of the hosts themselves must be fully taken into account. 


\section{Vole tuberculosis}

Vole tuberculosis (vole TB) is a chronic, endemic infection of field voles caused by Mycobacterium microti, a member of the $M$. tuberculosis complex (van Soolingen et al. 1998). Vole TB is a zoonotic infection, having been infrequently recorded in both immunocompromised and immunosuppressed humans (van Soolingen et al. 1998; Niemann et al. 2000; Emmanuel et al. 2007). In voles, TB causes severe clinical pathology in the later stages of the disease, characterized by externally visible cutaneous lesions (Cavanagh et al. 2002, 2004; Burthe et al. 2008b; Kipar et al. 2013). The definitive transmission route is unknown. However, wounding has been suggested due to the common occurrence of cutaneous lesions (Burthe et al. 2008b).

Prevalence of external signs of vole TB showed evidence of delayed density dependence (Cavanagh et al. 2004). However, this approach underestimated TB prevalence (Wells, 1946; Cavanagh et al. 2004; Burthe et al. 2008b). Post-mortem examination and culture of infected tissue samples from cross-sectional surveys indicated prevalence over twice that based solely on external signs, with up to $50 \%$ of voles infected in some sites (Cavanagh et al. 2002; Burthe et al. 2008b). Prevalence of infection increased with vole mass (a proxy for age) and hence prevalence was highest in spring when the population was mainly comprised of individuals over 6 months of age (Burthe et al. 2008b).

\section{Bartonella $s p p$.}

The bartonellae are gram-negative bacteria and facultative intraerythrocytic parasites of a wide range of mammalian species. Transmission mechanisms are not yet fully understood, but arthropods, often fleas, are important vectors (Birtles, 2005; Buffet et al. 2013; Morick et al. 2013). Several Bartonella species are associated with disease in humans or animals.

Up to five species of Bartonella circulate concurrently in woodland rodent communities in the $\mathrm{UK}$ (Birtles et al. 2001; Telfer et al. 2007a,b). Although small mammals have demonstrated a high (40-60\%) Bartonella prevalence (Birtles et al. 1994; Kosoy et al. 1997), infections are self-limiting and do not usually result in clinical disease (Telfer et al. 2008, 2010). In Kielder, contrasting dynamics of three Bartonella species have been recorded, with only Bartonella grahamii exhibiting a distinct seasonal pattern and the three species also differing in their likelihood of infecting young or mature hosts (Telfer et al. 2007a). Interestingly, all species in general exhibited stronger correlations with host dynamics than those of their vectors, supporting the assertion that flea-borne microparasites can often be incorporated effectively into epidemiological models as directly transmitted pathogens (Dye and Williams, 1995).

\section{Anaplasma phagocytophilum}

Anaplasma phagocytophilum is a an obligate intracellular bacterial parasite of granulocytes, which was historically associated with causing tick-borne fever in sheep and other livestock (Foggie, 1949; Hudson, 1950). In the 1990s, the zoonotic potential of A. phagocytophilum was realized (Chen et al. 1994), although different genetic variants appear to have restricted host ranges (Massung et al. 2003; Bown et al. 2009). Whilst little is known regarding the effects of $A$. phagocytophilum on rodents, it has wellestablished immunosuppressive effects on livestock (Woldehiwet, 2010). Rodents demonstrate no obvious clinical signs of infection, and longitudinal studies indicate that infection is short-lived, with the majority of individuals testing positive by PCR for only a single month (Bown et al. 2003, 2008). Infection prevalence in Kielder field voles may reach $12 \%$ in late summer but falls to zero over winter when no nymph or adult ticks are feeding (Bown et al. 2009).

Of the two most commonly found ticks in Kielder (see Ticks, below), transmission in small mammals appears to be at least predominantly via Ixodes trianguliceps rather than Ixodes ricinus, as the absence of $I$. ricinus had no significant effect on infection prevalence in field voles (Bown et al. 2008). Similarly, infection in both field voles and common shrews follows the seasonal dynamics of $I$. trianguliceps nymphs (Bown et al. 2003, 2009, 2011). Further genetic analyses indicated that distinct $A$. phagocytophilum genotypes exist in separate enzootic cycles, possibly as a result of vector specificity (Bown et al. 2009).

\section{Babesia microti}

Babesia microti is an intraerythrocytic protozoan parasite infecting wild rodents and the major causative agent of human babesiosis in the USA, a potentially fatal tick-borne zoonosis. In common with other members of the Babesia genus, B. microt $i$ requires an ixodid tick vector for the sexual stage of its life cycle. In the UK, this has been identified as I. trianguliceps (Randolph, 1991). The great host-specificity of this nest-dwelling tick, which does not readily bite humans, may explain the lack of human B. microti infections in Europe. However, the human-biting tick $I$. ricinus is sympatric with I. trianguliceps in many areas, including Kielder (see Ticks) and may provide a route for transmission to humans.

Babesia microti infections in field voles are usually sub-clinical and persistent, with longitudinal studies 
demonstrating that individuals testing PCR positive remain so for all subsequent captures (Bown et al. 2008; Telfer et al. 2008). Interestingly, laboratory studies on related bank voles suggest that whilst infections are chronic, sufficient parasitaemia for transmission to ticks to occur is restricted to a window of only 1-4 days post infection (Randolph, $1995)$. Infection prevalence may reach over $40 \%$ in Kielder field vole populations (Bown et al. 2008; Telfer et al. 2008) and probability of infection has a non-linear relationship with weight, with individuals of $20 \mathrm{~g}$ being at highest risk of becoming infected (Telfer et al. 2008).

\section{Trypanosoma (Herpestoma) microti}

Trypanosoma microti is a stercorarian trypanosome specific to voles (Noyes et al. 2002). Trypanosome infections in rodents are generally considered to be of low pathogenicity, but there is some evidence that trypanosomes can cause anaemia in microtine rodents and detrimentally affect female reproduction (Wiger, 1977).

In Kielder, T. microti prevalence is highly seasonal, being highest in late summer/autumn and lowest in spring (Smith et al. 2005). Trypanosoma microti is transmitted by fleas and a positive association between trypanosome prevalence and flea infestation in the previous 1-3 months has been observed in Kielder field voles (Smith et al. 2005). Following ingestion of the parasite during a blood meal, it develops in the flea hindgut before being shed in the feces. Infection of a new vole host can then occur via fecal contamination of the skin, or through accidental ingestion of fleas or their feces (Albright and Albright, 1991). However, a study in which flea prevalence was experimentally manipulated demonstrated that vector-independent transmission of $T$. microti, most likely though mechanical transmission as a result of aggressive behaviour, is also of epidemiological significance in Kielder (Smith et al. 2006).

\section{Ticks (Ixodida)}

Ticks are amongst the most important arthropod vectors and, as described above, are responsible for $B$. microti and A. phagocytophilum transmission among Kielder voles. In the UK, at least five species of tick may feed on rodents (Snow, 1979) of which two, I. ricinus and $I$. trianguliceps, are frequently encountered at Kielder (Bown et al. 2006, 2008, 2009). Whilst all three stages of $I$. trianguliceps feed upon small mammals (Randolph, 1975), I. ricinus is more catholic in its feeding behaviour, feeding on a wide variety of hosts including reptiles, birds and mammals (Arthur, 1963). As such, the exclusion of deer from an area significantly reduced the abundance of $I$. ricinus, but had no detectable effect on I. trianguliceps (Bown et al. 2008).

Longitudinal studies indicate that the majority of larvae recorded on field voles were $I$. ricinus whilst adult ticks were almost exclusively $I$. trianguliceps (Bown et al. 2009). Seasonal fluctuations in the abundance of ticks feeding on voles were apparent, with peaks of $I$. ricinus larvae in late spring/early summer, whilst I. trianguliceps larvae peak abundance occurs in late autumn (Bown et al. 2009). Nymph and adult ticks were recorded in much lower numbers with no obvious peak, but were largely absent between November and April (Bown et al. 2009). Male voles were more likely to be infested with nymphal or adult ticks, and mature males were more likely to be infested with larvae of either tick species (Bown et al. 2008). The presence of larvae increased the probability of nymphs or adults on a vole and vice versa (Bown et al. 2008).

\section{Fleas (Siphonaptera)}

A number of rodent-specific and generalist flea species are known to inhabit Kielder Forest, including Peromyscopsylla spectabilis, Ctenophthalmus nobilis vulgaris, Megabothris walkeri, Malaraeus penicilliger, Rhadinopsylla pentacanthi and the largest British species, the mole flea (Hystrichopsylla talpae talpae) (Smith et al. 2005; Jackson et al. 2011; Turner et al. 2011). Fleas which commonly infest field voles exhibit seasonal dynamics and are known to peak in mid-late summer (Smith et al. 2005). Within Kielder, these species have thus far primarily been studied in the context of their transmission of Bartonella spp. and T. microti (see preceding sections). However, Telfer et al. (2007a) demonstrated that the probability of flea infestation is density- and delayed density-dependent; voles from clear-cut sites with high densities the preceding autumn were more likely to be infested. Conversely, field voles were less likely to be infested if found in a currently or recently high-density population, suggesting an intra-specific dilution effect whereby the flea population is divided among a greater number of hosts.

\section{Others}

Many other endemic pathogens and parasites of the Kielder field voles are known but have not yet been studied in great detail (see Table 2 for a summary of known macroparasites). However, genetic associations with resistance to nematodes and cestodes have been examined (see Genetics section). Research into the impact of these less well-studied pathogens is ongoing, and there will undoubtedly be currently undiagnosed pathogens circulating within the field 
Table 2. Macroparasite species observed in Kielder Forest field voles

\begin{tabular}{ll}
\hline \hline Nematodes & Syphacia nigeriana \\
& Trichuris arvicolae \\
& Heligmosomoides laevis \\
Cestodes & Taenia polyacantha \\
& Taenia taeniaeformis \\
& Taenia mustelae \\
& Anoplocephaloides dentata aff. \\
& Paranoplocephala sp. \\
& Rodentolepis (=Hymenolepsis) asymmetrica \\
& Arostrilepis horrida \\
& Laelapidae \\
Mites & Listrophoridae \\
& Myobiidae \\
& Ear mites \\
Lice & Hoplopluera acanthopus \\
\hline \hline
\end{tabular}

vole populations, particularly microparasites, which will warrant further study.

\section{TRANSMISSION DYNAMICS}

Our work on transmission dynamics, largely focused on cowpox virus and aimed at testing widely held theoretical assumptions using empirical data, began on the Liverpool time series. We initially performed a rather unsophisticated analysis of numbers of infected and susceptible hosts to examine the transmission dynamics of cowpox virus (Begon et al. 1998, 1999). We examined dynamics within both wood mice and bank voles to ask, first, whether the densitydependent mode of transmission conventionally assumed-especially in modelling studies-for directly but not sexually transmitted infections, was in fact appropriate (as opposed, for example, to frequency-dependence, where the contact rate between hosts is assumed to remain constant irrespective of density). We also compared transmission rates within and between species. This is important for two reasons: first, for the insights it provides on whether coexisting wildlife hosts should be considered joint or independent reservoirs of infection, and hence whether interspecific dilution or amplification effects are possible (Begon, 2008). Second, it allows an assessment to be made from field data of the strength of 'apparent competition' in a host-host-pathogen system, whereas previously this has largely been the subject of theoretical analysis (e.g. Begon and Bowers, 1994). Aspects of the same questions were also examined by the analysis of spatiotemporal cowpox data to assess, first within species, the spatial and temporal scales over which an infectious individual poses a risk of infection to a susceptible one (Carslake et al. 2005). The same technique was then applied between species (Carslake et al. 2006), in both cases asking, in essence, 'who acquires infection from whom?'.
The results called into serious question the assumption that susceptible and infectious hosts mix at random and hence that transmission of cowpox virus is 'density-dependent'. Our time series analysis, for each species in isolation, indicated that frequency-dependent transmission (conventionally assumed to apply to sexually transmitted diseases) was superior to density-dependent transmission as a descriptor of the dynamics (Begon et al. 1998). A $K$-function analysis confirmed that an infectious individual posed a measurable risk of infection for a period roughly equal to the infectious period itself, about 4 weeks. It also indicated that this risk was detectable only at spatial scales within the species' known home ranges (Carslake et al. 2005). These results therefore suggest a rather general conclusion, namely that random mixing may have been too readily assumed, and that many diseases that are not sexually transmitted may nonetheless be socially transmitted, with essentially the same transmission dynamics.

Moreover, the time series analysis of the two species together indicated that between-species transmission was rare, in spite of the species occupying not only the same general habitat but often even sharing burrows (Begon et al. 1999). The $K$-function analysis confirmed this (Carslake et al. 2006). Thus, for cowpox virus at least, bank voles and wood mice act as effectively independent reservoirs. Similarly, while the potential for apparent competition between bank voles and wood mice mediated by cowpox virus undoubtedly exists, since the virus depresses the birth rate and possibly the survival of both host species (see Fitness effects section), it is likely to be insignificant in practice because the pathogen is so rarely transmitted from one species to the other.

A further study connected to these was carried out by Telfer et al. (2005a) examining the interaction between bank voles and wood mice and two of their shared pathogens, Bartonella birtlesii and Bartonella taylorii, in Ireland. The prevalence of both, which occur only in wood mice in Ireland, declined significantly with bank vole density. Results were therefore consistent with there being a dilution effect (Norman et al. 1999), a phenomenon which despite its high profile and the recent controversy it has attracted (e.g. Randolph and Dobson, 2012) is still short of good case studies (see Fleas section for an example of another possible dilution effect in Kielder).

Although the Kielder time series could not further our understanding of between-species dynamics, focusing as it did on a single species, it was possible to use the field vole data to examine much more thoroughly the question of the nature of the transmission function itself (Smith et al. 2009). Rather than simply comparing density- and frequency-dependent transmission, the analysis asked 
where on the spectrum between density- and frequency-dependence the true function might be, and also whether that functional form, or indeed the strength of transmission itself, might vary seasonally. In fact, results showed that, overall, transmission of cowpox virus amongst field voles was neither frequency- nor density-dependent. On a scale encompassing 0 (density-dependence) and 1 (frequency-dependence), the observed value of the scaling exponent relating contact rate to density was $0 \cdot 62$. This was significantly different from both 0 and 1 (credibility interval $0 \cdot 49-0 \cdot 74$ ), appropriate for a transmission function that increases linearly with host density at lower densities (density-dependence) but tends to saturate as density increases further (approaching frequency-dependence).

Furthermore, when models were examined that allowed parameters to vary seasonally, it appeared, first, that transmission was more readily achieved in winter, perhaps because susceptibility to infection is greatest then. Secondly, the overall picture of transmission lying between density- and frequencydependence seemed to be hiding a pattern in which transmission was closer to density-dependence in the winter and closer to frequency-dependence in the summer. This is plausible insofar as field voles defend territories much more actively in the breeding season (summer), such that contact will be with neighbours and hence relatively independent of overall density. In winter, mixing is not so constrained, hence contact rates can indeed be expected to increase with density. Repeatedly, therefore, these transmission studies, whether within or between species, have emphasized that once data are collected from natural populations, conventional, widely held assumptions may be found wanting.

\section{FITNESS EFFECTS OF INFECTION}

The impact of endemic infections on the fitness of hosts in the wild is poorly understood, with studies tending to be cross-sectional or to focus on epidemic or emerging infections. Changes in host population dynamics may arise through impacts on host survival and/or fecundity rates. Longitudinal, experimental and modelling work investigating the prevalence of a suite of pathogens in field voles at Kielder has greatly advanced our understanding of the impacts of endemic infections, indicating that negative fitness costs can be biologically significant.

Evidence from Kielder suggests that endemic infections negatively impact field vole survival. Individuals infected with cowpox virus had a $22 \%$ lower probability of survival than uninfected individuals and, at the population level, survival rates were negatively correlated with cowpox prevalence (Burthe et al. 2008a). There is also some suggestion that TB has a negative impact on survival (Burthe et al. 2008b). While not statistically significant, survival of voles following the appearance of an external lesion characteristic of advanced vole tuberculosis tended to be lower than for voles without lesions. As discussed earlier, diagnosis of disease based on lesions underestimates the prevalence of infection and hence the negative impact of late-stage TB would be underestimated due to individuals dying before presenting overt late-stage disease symptoms. A significant decline in body condition of individuals at the time of appearance of the first external lesion further suggests that TB may potentially impact individual fitness. Further effects of infection on host condition are discussed in the next section.

Impacts on host reproduction by pathogens have proven difficult to evaluate due to difficulties in assigning juveniles to parents and measuring reproductive success. However, prevalence of trypanosomes was found to be highest in heavier (older) animals at first capture compared with heavier recaptured animals suggesting that infected animals may be less likely to become territory holders and therefore less likely to breed (Smith et al. 2005).

In related work on bank voles and wood mice in the Liverpool populations, cowpox virus infection was both positively and negatively associated with survival, depending on the season; survival rates increased with cowpox prevalence in the summer but decreased during the winter (Telfer et al. 2002). This may be related to subtle interactions with effects of cowpox virus on reproduction in these species. Female bank voles and wood mice infected with cowpox virus have been shown to delay maturation, and therefore reproduction, often until the following year (Telfer et al. 2005b), a response also observed in the laboratory (Feore et al. 1997). This delay in reproduction, and the associated energetic costs saved, may be the reason for the increased survival rates for cowpox-infected compared with non-infected individuals in summer.

Modelling work suggests that, theoretically, reduced or delayed fecundity following recovery from infection can influence host population dynamics and induce multi-year cycles if, due to infection, individuals miss the time-window for sexual maturation in their birth year and are thus first able to reproduce the following spring (Smith et al. 2008). However, empirical investigation of parameters such as variation in the onset of maturity in infected hosts relative to uninfected hosts would be necessary to support this theoretical prediction.

As discussed in more detail below (see Coinfection), the field vole data indicate clearly that infection with one pathogen may frequently imply co-infection with others. The fitness consequences of infection with, say, cowpox virus, may therefore, in practice, be the fitness consequences of infection with cowpox virus and all the other parasites that are consequently more likely to be found in the same 
host. This sets limits on the relevance of controlled experiments in the animal house on the effects of parasites on host fitness. It also emphasizes that there may often be no clear link between the clinical effects of an individual parasite species and the effects it has on host fitness in statistical analyses carried out at the population level.

\section{HAEMATOLOGY AND MEASURES}

OFHOST CONDITION

Variation among individuals and populations in health status and immunocompetence (a host's general ability to resist or tolerate infection) may influence parasite dynamics, as a result of variable susceptibility to infection (see Immunology and Genetics sections for studies on the immunological and genetic basis of this variation). In human and veterinary medicine the health status of individuals is routinely monitored by measuring selected physiological indices, and haematological parameters are among the indices most extensively used. Nonetheless, the wealth of information they can provide has not always been fully exploited in wildlife populations.

The cellular component of the blood consists of various cell types, each of which has a different function and responds distinctively to infection, stress, nutritional deficit, etc. Although the interpretation of these parameters requires caution, in general, red blood cells (erythrocytes, RBCs) and lymphocytes are important indicators of general health and condition, while the other white blood cells (WBCs) are components of different types of immune responses (Tizard, 2004). Low concentrations of RBCs, caused by blood loss, haemolysis or decreased erythrocyte production, result mainly from deficient nourishment and infection or parasitism (Stockham and Scott, 2002). Lymphocytes, the effectors of acquired immunity, proliferate in response to antigenic stimuli and have a long lifespan in blood, while their numbers decrease (lymphocytopenia) during immunosuppression by glucocorticoids or immunosuppressive infections (Feldman et al. 2000; Stockham and Scott, 2002). Therefore, circulating levels of lymphocytes may be useful indicators of current immunological investment. Of the remaining WBCs, blood concentrations of neutrophils increase rapidly as a response to cytokines released during tissue injury and bacterial infection (Tizard, 2004). They are useful proxies for acute inflammatory responses as their levels return to normal soon after antigenic stimulation ceases. Monocytes are found in high concentrations in subacute and chronic inflammatory response caused by bacterial or protozoan infections (Feldman et al. 2000; Tizard, 2004).

By evaluating indices of health in wild populations, our knowledge of the dynamics of health and infection may be understood more clearly. Beldomenico et al. (2008b) investigated haematological dynamics within the Kielder field voles, to determine environmental and host factors associated with indicators of inflammatory response (counts of monocytes and neutrophils) and of condition (lymphocyte and red blood cell counts). Individuals from three field vole populations were sampled monthly for 2 years. Comparisons with individuals kept under controlled conditions facilitated interpretation of field data (Beldomenico et al. 2008b).

In comparison with humans and domestic animals, which maintain their haematological parameters within constant 'normal' ranges while in health, these parameters appeared to be highly variable in wild field voles. This may imply a more widespread distinction between the range of environments experienced by individuals typically found in natural vertebrate populations and those experienced under controlled or cosseted conditions. There was a strong seasonal variation that persisted even after environmental and host factors usually associated with blood cell count variation were considered in the analysis. There were three well-characterized 'physiological' seasons. The immunological investment appeared lowest in winter (lowest lymphocyte counts), but red blood cells were at their highest levels and indices of inflammatory response at their lowest, indicating a low infection risk during this period. Spring, when acquisition of breeding territories is expected to lead to acute competition for space and increased aggressive behaviour, was characterized by dramatic changes, with a steep fall in red blood cell counts and peaks in indicators of inflammatory response. During the course of summer-autumn, the parameters gradually returned to their previous levels; red blood cell counts recovered and the indicators of inflammatory response decreased, while the immunological investment increased.

All the haematological parameters were lower in individuals in poor body condition and when preceding population densities were higher. Moreover, the first pregnant females of the year were those with higher values of the haematological metrics, emphasizing the important role of energetics in population dynamics. Indeed, even when RBC counts were 'high' in the field, they were lower than in the near-optimal conditions of the animal house (abundant food and low parasitism/infection), suggesting that voles in the natural populations were generally resource and/or energy-limited, and they could therefore only increase their investment in, for instance, neutrophils by a compensatory decrease in their investment in other functions (e.g. the production of RBCs) (Beldomenico et al. 2008b).

Azurocytes (AZ) are lymphocytes specific to microtine rodents which closely resemble natural killer (NK) cells. They are particularly common in late pregnancy and inducible by progestins both in 
males and females (Mihok et al. 1987; Mihok and Schwartz, 1991). Beldomenico et al. (2008c) found that the counts of $\mathrm{AZ}$ were indeed much higher in pregnant females, and that these counts were positively correlated with past vole density. Males had low prevalences and counts, both for breeding and non-breeding individuals, but they showed a seasonality that varied with age, body condition, and current and past vole density. Also, the occurrence of $\mathrm{AZ}$ in males was more likely after they had had low levels of indicators of condition (see following section), suggesting that in males these cells predominantly result from a response to infection.

The strong seasonal variation in health dynamics pinpoints the spring as a period of increased vulnerability, both to infection and other causes of mortality. When population densities have previously been low and body condition is good, female field voles begin reproducing early (Ergon et al. 2011). Preceding high densities are followed by a negative impact on all blood cell types, except for AZ in females. Host condition in spring may therefore not only reflect but also determine, in part, whether a year will be in an increase or a decrease phase of the abundance cycle.

VICIOUS CIRCLES: SYNERGY BETWEEN CONDITION AND INFECTION

The previous section discussed effects of infection on host fitness and condition. Equally, a host's condition may affect its propensity to become and to remain infected. Contact between susceptible hosts and either infectious hosts, vectors or environmental reservoirs is crucial in determining infection risk. However, following exposure to a pathogen, a continuum of outcomes might be seen within a host, ranging from failure of the infection to progress to overwhelmingly high infection intensity. The outcome may depend on characteristics of the pathogen (e.g. strain, infective dose) or of the host (e.g. genotype, condition).

As discussed earlier, the Kielder field voles exhibit characteristic periodic peaks followed by declines, and these dynamics are associated with food shortage and poor condition (Huitu et al. 2007). To test the hypothesis that poor host condition increases infection risk, Beldomenico et al. (2008a) used longitudinal data from replicated wild field vole populations to evaluate whether individuals with reduced indicators of condition were more likely to become infected. Because the community of obligate and facultative parasites to which field voles are exposed is highly diverse, exhaustively testing for all infections is impossible. To overcome this problem, initially generic indices that capture the physiological response to infection were used. Elevated neutrophil counts (neutrophilia) are an indication of acute inflammatory response associated with bacterial infection, and high monocyte counts (monocytosis) are expected in subacute and chronic inflammatory response caused by infections with bacteria or protozoans (Feldman et al. 2000). In addition, low peripheral lymphocyte counts (lymphocytopenia, an indication of immunosuppression or poor immunological investment) or low red blood cell (RBC) counts (anaemia, an indication of poor aerobic capacity) were used as haematological indicators of condition (see Haematology). The results showed that poor condition increases the probability of infection: individuals with anaemia and lymphocytopenia had increased probabilities of developing monocytosis and higher increments in neutrophils when resampled 4 weeks later (Beldomenico et al. 2008a).

The results above provide evidence supporting Lochmiller's hypothesis (Lochmiller, 1996), which states that opportunistic pathogens take advantage of altered host immunocompetence (see Immunology section for further discussion on the concept of immunocompetence) during stress periods, consequently regulating wild animal populations. To test this hypothesis in the Kielder system, Beldomenico et al. (2009a) carried out a nested case-control study that assessed whether susceptible individuals (those who had never had cowpox) with poorer body condition (low degree of fat and muscle cover) had higher probabilities of contracting cowpox over a 4-week period. The results were particularly striking for males. For males caught at the same time, a susceptible individual with poor body condition was twice as likely to contract cowpox as a susceptible male with good body condition; if this individual was also anaemic, the chances were almost quadrupled (Fig. 3). This result supported Lochmiller's hypothesis, and further demonstrated that it holds not only for opportunistic pathogens, but here for an endemic virus.

If this condition-dependent infection risk originates from a reduced resistance of the host, it will not only result in greater propensity to becoming infected of those that are in poorer condition; it may also cause infections of higher intensity, thus resulting in individuals that suffer a more severe disease and are a more significant source of infection. Beldomenico et al. (2009b) assessed this hypothesis by investigating the temporal relationship between host condition and intensity of infection by the protozoan Trypanosoma (Herpestoma) microti in wild field vole populations. The individuals that developed high levels of parasitaemia were those that had very low lymphocyte counts one month previously.

As noted above, not only can poor host condition predispose individuals to infection; infection itself can have a detrimental effect on condition. Besides their specific pathogenic effects, parasites extract host resources and induce a nutritionally demanding immune response (Sheldon and Verhulst, 1996; Lochmiller and Deerenberg, 2000). There is a clear 


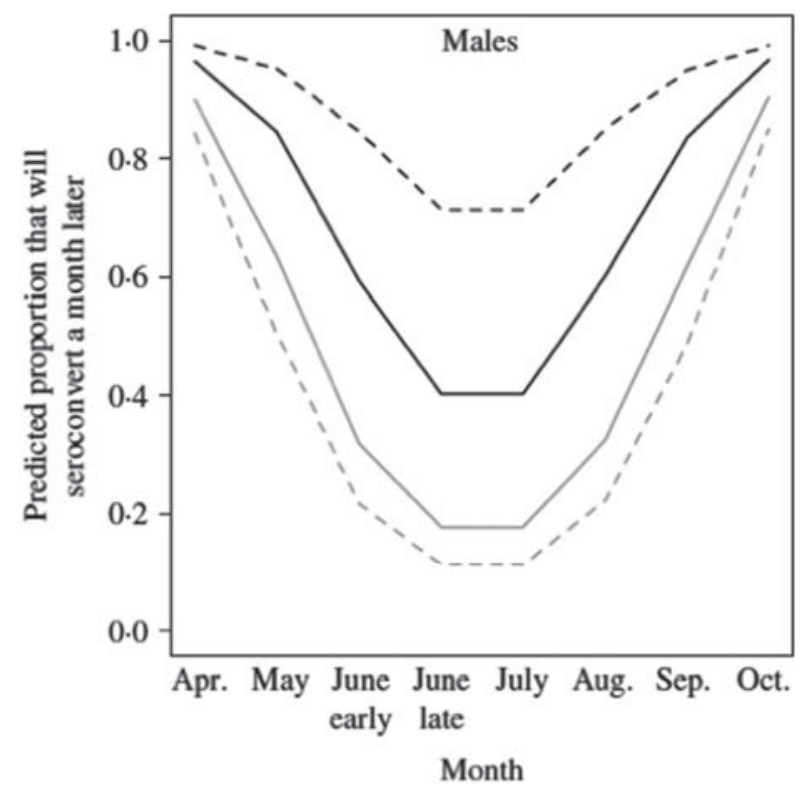

Fig. 3. Predicted probability of seroconverting for male field voles from Kielder. Variation by month, body condition score $(4=$ black lines; $8=$ grey lines $)$ and red blood cells (RBCs) (past density fixed at 50). In the simulation, anaemic (dashed lines) represents individuals with 3 million RBCs $\mathrm{mL}^{-1}$, and normocytic (solid lines) represents voles with 8 million $\mathrm{RBCs} \mathrm{mL}^{-1}$. Modified from Beldomenico et al. (2009b).

potential for synergy: poor condition predisposes individuals to infections, which further reduces the condition of the host, which further predisposes the host to infection, and so on. Thus, as previously noted, at the individual level, low haematological indicators of condition precede elevated levels of haematological indicators of infection in wild field voles. However, those individuals with high indicators of infection subsequently experience a decline in their indicators of condition (Beldomenico et al. 2008a). Furthermore, because individuals in poorer condition are expected to have infections of greater intensity, the resulting deterioration in condition is likely to be even more marked for infections in individuals with a preceding impoverished condition. This was supported by our study on trypanosome dynamics: field voles with decreased indicators of immunological investment developed high intensities of T. microti parasitaemia, and subsequently, further declines of these indicators were observed (Beldomenico et al. 2009b).

The above suggests that small initial differences in host condition caused by resource shortage, competition etc. can become exaggerated and populations might become 'polarized' into the weak and the strong (Beldomenico and Begon, 2010). Vicious circles emerge, whereby an individual with an impoverished condition is more prone to developing infections, which are also more likely to be severe; in turn, this results in further deterioration in condition that can eventually and substantially affect its performance and survival. At the population level, a high proportion of individuals in poor condition may cause both a large number of infections and more severe infections, resulting in pathogen exposure dose being greater, with a consequential greater impact on host dynamics (Beldomenico and Begon, 2010). Similar results have been reported in other systems including an observational study on fish (Blanchet et al. 2009) and a field-experimental study on mice (Pedersen and Greives, 2008).

These reciprocal effects between host condition and infection might indeed be the mechanism by which parasites exert a control on their host populations, as hosts tend to be more stressed and in poorer condition (thus becoming more vulnerable to their parasites) when their densities are high (Huitu et al. 2007; Beldomenico et al. 2008b).

\section{CO-INFECTION}

While most of the studies at Kielder have focused, as they have in other systems, on a single species of pathogen (and of host), there is no doubt that most hosts, most of the time, are infected by a multiplicity of parasites and pathogens. Questions naturally arise, therefore, regarding the effects of one infection on another. Indeed, some such effects may also occur when infections are consecutive rather than simultaneous. The probability, intensity and length of one infection may be altered by the presence of, or repercussions from, another, as may any effects on host fitness. The idea of 'vicious circles' (above) carries within it the implicit acknowledgement that individual infections cannot be considered in isolation.

Experiments in laboratory model systems have demonstrated effects of co-infection on host susceptibility, infection length, and intensity and clinical signs. Studies in wildlife populations and humans, while establishing firmly that positive and negative associations can occur between parasites, have tended to be cross-sectional, with each host providing infection data at one time point only. The time of initial infection is unknown in such studies. There is, therefore, limited scope for determining whether patterns reflect inherent differences between hosts in either susceptibility or exposure to infection, rather than interactions (Telfer et al. 2008), or for exploring the impact of infection sequence (Jackson et al. 2006). Consequently, in natural populations, the relative importance of interspecific interactions, compared with other factors, in determining the dynamics and structure of parasite communities is only poorly understood.

Telfer et al. (2010) used the field vole dataset to examine individual infection risks for a community of microparasites consisting of cowpox virus, Babesia microti, the Bartonella species taken as a group and 


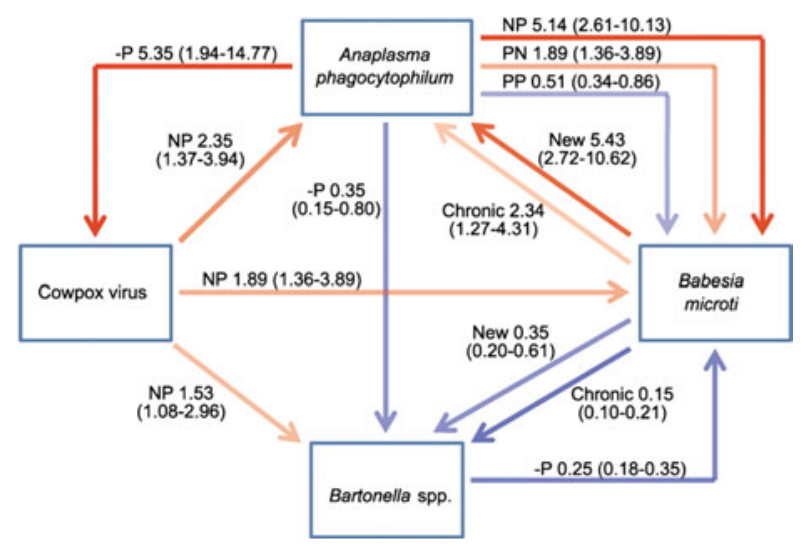

Fig. 4. The web of interactions and magnitude of effects between microparasite species in the Kielder field voles. Positive associations (odds ratio $[\mathrm{OR}]>1$ ) are in red, negative associations $(\mathrm{OR}<1)$ in blue, with intensity of line reflecting the magnitude of an effect. $95 \%$ confidence intervals of OR shown in parentheses. Infection history associated with effect also noted: $\mathrm{N}=$ negative,

$\mathrm{P}=$ positive. NP therefore signifies no infection at $t_{-1}$ and infection at $t_{0}$. Thus, for example, individuals with chronic $B$. microti infections are $\sim 2$ times more likely to be infected with $A$. phagocytophilum (OR $=2 \cdot 34$ ) while those with new $B$. microti infection are $\sim 5$ times more likely to be infected $(\mathrm{OR}=5 \cdot 43)$. From Telfer et al . (2010).

A. phagocytophilum. Infection risk will depend on both the probability of encountering an infectious dose and the probability of infection given exposure (host susceptibility). The aim was to determine whether susceptibility to infection by one microparasite species was influenced by others. Therefore, for each microparasite, the study investigated whether the other microparasites influenced the probability that a susceptible animal became infected at a given time point $\left(t_{0}\right)$. It did so by adding infection status for these other pathogens as explanatory variables to baseline statistical models that accounted for environmental and individual variables (sex, season etc.). This method minimizes the risk of detecting spurious associations, which, in reality, reflect correlated exposure risk (e.g. a positive association simply because both parasites are most prevalent in late summer).

It was apparent that this community of parasites represents an interconnected web of interactions: effects of other infections on infection risk were both strong and widespread, and connectance within the parasite community was exceptionally high, with evidence detected for all possible pair-wise interactions (Fig. 4). Both positive and negative associations were detected, and their magnitude was frequently considerable: up to $5 \cdot 5$-fold increases in risk and reductions in the odds of becoming infected of the order of $15 \%$ compared with uninfected individuals (Fig. 4). Indeed, perhaps most strikingly, in all cases except for cowpox, infection with other parasite species explained more variation in infection risk than factors related to exposure risk and host condition, such as age and season. Moreover, the sizes of the effects of other parasites on infection risk were also similar to, and frequently greater than, other factors. For example, of all the non-infection variables, season generally had the largest effect on infection risk, with seasonal increases in infection probability ranging from approximately 3 -fold (A. phagocytophilum) to 15 -fold (B. microti); but these were broadly matched by the magnitude of infection effects (Fig. 4). These results are not explicable by simple co-occurrence of infections in hosts in poor condition since, for a subset of the data, individual variation in indices of host body and haematological condition at the time of infection were explicitly accounted for, and there was no evidence of any reduction in the strength of between-parasite interactions.

Several infections increased susceptibility to other microparasites (Telfer et al. 2010). Jackson et al. (2009) have shown previously that naturally occurring parasites are capable of exerting immunomodulatory effects on wild rodents, and release from effective control by the immune system is perhaps therefore the most likely explanation, especially when supported by experimental studies. For example, laboratory studies have indicated the importance of immunomodulation for host exploitation by pox viruses (Seet et al. 2003), which may explain the positive effect of cowpox virus on susceptibility to other parasites. The same immune-mediated mechanisms might also account for an earlier demonstration that cowpox virus increases the length of Bar. taylorii infections (Telfer et al. 2008). Thus, mechanisms responsible for increasing susceptibility may also prolong infections in those that do succumb.

Strong reductions in susceptibility caused by other infections were also observed. The largest effect overall was reduced susceptibility to Bartonella spp. in individuals infected with Bab. microti, and was especially apparent in chronically infected animals, where the odds of infection were $15 \%$ of those of uninfected animals (Fig. 4). Resource depletion may play a role here, as both species target erythrocytes (Table 1). Alternatively, negative effects may reflect up-regulation of mediators of a cross-effective Th1 response and therefore could represent an example of immunologically driven ecological interference (see Immunology and Genetics sections, below).

The study by Telfer et al. demonstrates, therefore, that communities of microparasites are structured by strong interactions between species, providing the first evidence from natural populations that such interactions can be driven by effects on susceptibility and have as much impact on infection risk as more commonly considered factors such as host age and season. As field voles are also infected by macroparasites (Table 2), as well as other microparasites, it is likely that the identified relationships 
represent just one part of an even larger web of interactions. These results also emphasize that the standard practice of classifying individuals in natural populations as infected or uninfected by one parasite alone fails to recognize that much more may be implied by the categorization 'infected'. For example, as we note above, cowpox virus infection has been associated with major reductions in survival and fecundity. However, in the co-infection study, 39\% of those infected with cowpox virus were also infected with B. microti, $65 \%$ of the remainder had Bartonella spp. infections, and overall, $79 \%$ were co-infected with at least one of the three microparasites considered. Clearly, even when significant associations between a given infection and host fitness are detected in a wildlife host, attributing the effect to that parasite alone may be unjustified.

A subsequent study applied more sophisticated and novel statistical techniques to the dataset from March 2005-March 2007 and dealt separately with three Bartonella species, Bartonella doshiae, B. grahamii and B. taylorii (Sherlock et al. 2013). While broadly confirming previous findings, this new analysis highlighted some possible discrepancies with previous analyses. Once again, Bab. microti increased the likelihood of contracting all three Bartonella species, whether the $B$. microti infection was acute or chronic. This time, moreover, B. microti was also seen to decrease the chances of recovery from all three Bartonella infections: that is, Bartonella infections were longer when B. microti was also present. This had previously also been suggested in the case of Bar. taylorii (Telfer et al. 2008). It is important to recognize that the consequences of one infection extending the length of another-in terms of the period of time host fitness may be affected and the parasite transmitted-may easily be as profound as those of simply increasing susceptibility. In this subsequent study, however, there was no evidence of the reverse interaction: Bartonella increasing susceptibility to $B$. microti. This runs counter to the Telfer et al. (2010) study and suggests that the effect of Bartonella on B. microti noted by the authors may be a statistical artefact arising from the extremely strong effects of B. microti on Bartonella (Sherlock et al. 2013).

This study also allowed interactions among different, co-infecting Bartonella species to be examined for the first time. Notably, voles that had previously been infected with $B$. taylorii were less likely to contract infections of either B. grahamii or B. doshiae. The suggestion that this positive interaction between the species may be the result of cross-immunity is supported by evidence from the analysis of an effective immune response to Bartonella infections more generally: voles previously infected with either B. grahamii or B. taylorii were less likely to re-contract the same infection. This in turn makes the more general point that patterns of co-infection, particularly in longitudinal data, can suggest or even support particular processes giving rise to them, but understanding co-infection is likely, ultimately, to require those processes to be examined directly. One important class of processes, those acting through the immune system, is examined next.

\section{IMMUNOLOGY}

Traditionally, research into wildlife immunology has concentrated on broad definitions and single measurements of 'immunocompetence' (such as phytohaemagglutinin-induced swelling). However, as we have discussed in previous sections, host-pathogen interactions are dynamic and context dependent; 'resistance' is therefore unlikely to be accurately represented by a single, simplified immunological measure (Demas et al. 2011). Post-genomic technologies now allow us to define immune variability much more precisely in naturally occurring non-model organisms and move beyond this simplified view of immunocompetence. Wild rodents, in particular, represent an exciting model for this expanded 'wild immunology' as researchers can capitalize on the immunological and genetic resources developed for laboratory rodents. Thus, measurements of the expression of genes or gene products underpinning immunological traits may be linked to environmental causes and to life history consequences for the individual. In the Kielder field voles, where responses to infection have been the central interest, we have focused on variability in the immune system as the possible key to individual variation in the response to infection.

Our approach to measurement has made a break from traditional ecological immunology (Bradley and Jackson, 2008) by considering immune function explicitly from a perspective derived from studies of the laboratory mouse. Thus, the immune system is considered as a multi-faceted defensive apparatus with different arms that drive different types of immune responses. For example, this includes the different T-helper (Th) cell phenotypes: Th1 cells drive responses against intracellular microbes, Th2 cells those against macroparasites, Th17 cells drive responses against extracellular bacteria, and regulatory $\mathrm{Th}$ cells exert immunosuppressive responses (Reiner, 2007). These different arms of the immune system may trade-off with each other and with other life history components for resources and there may also be complex functional cross-talk (cross-regulation) within the immune system itself and between immune responses and other traits.

The broad aim of the Kielder immunology studies has been to analytically decompose immune system function through measurements of different effector arms and to link these measurements to environmental causes and life history responses. Developing appropriate measurement strategies is a central 
difficulty, though, in analysing the immune system in naturally occurring non-model organisms. In our initial studies we were hampered by the lack of species-specific antibody reagents and by a deficit of genomic information for $M$. agrestis. However, by de novo sequencing using traditional PCR methods, we were able to design real-time PCR expression assays for a panel of immunological genes reflecting different immunological pathways (Jackson et al. 2011). These measurements were used both on in vivo (peripheral blood) samples from repeatsampled animals and in cultured splenocytes from destructively sampled animals. Culturing of splenocytes allowed stimulation of the cells with defined stimulants (e.g. mitogen, Toll-like receptor (TLR) agonists), in order to selectively stimulate immunological pathways and cell populations and measure latent (un-deployed) responsiveness (Jackson et al. 2011).

We combined these measurement approaches with interwoven longitudinal and cross-sectional sampling protocols in replicated habitats (see Datasets), for which detailed infection and biometric variables were recorded, in addition to immunological measurements. This hybrid study design exploited the respective strengths of the different types of sampling: on the one hand, destructive crosssectional sampling allows a wider range of more precise immunological, biometric and infection measurements; on the other, longitudinal sampling allows stronger inference of cause and effect (cause typically preceding effect in time series data).

A preliminary proof-of-concept study based on a single season of cross-sectional data (2008-2009) from two field sites discovered significant nonperiodic temporal trends in immune gene expression (Jackson et al. 2011). Expression of interferon regulatory factor 5 ( I vf5), which is important in anti-viral and pro-inflammatory anti-microbial responses (Paun et al. 2008), declined across the study period. Some other genes, including transforming growth factor beta 1 ( $T g f b 1$; a regulatory cytokine) and interleukin 2 (Il2), interferon gamma (Ifng) and T-box 21 (Tbx21/Tbet) (each involved in Th1 responses) showed expression that was higher in the winter of 2009 than the preceding winter. Both of these observations suggest systematic differences in environmental pressures on the immune system from year to year. Other variation (for example, expression of interleukin-1 $\beta[I l 1 b]$, involved in innate inflammatory responses) followed a pattern not inconsistent with a predictable annual/seasonal oscillation, although this would require corroboration in a longer time series. At the level of individuals we have found negative associations between the expression of proinflammatory mediators (Ifng, Illb) and some individual condition indices (haematocrit and organ weight residuals on body length). This might, in part, reflect a cost of resistance mediated by inflammation or the adverse effect of immunogenic infections themselves. We also found significant variation between life history stages (especially between immature and mature males and between pregnant and other females).

In the first instance, this early analysis (which did not consider infection variables) has shown that the measurement approaches we adopted can identify systematic variation in the immune expression patterns of populations and individuals. It will be the aim of our future work to use longer observational time series (a full 2 years of cross-sectional and longitudinal immune expression, biometric and infection data are currently available) and experimental field manipulations to link this variation to its environmental drivers and to its consequences for co-infection patterns and life history traits in individuals. In doing so we will begin to better understand the immune system as a complex trait within an ecological context, but may also be able to use immune expression responses as biomarkers to track important ecological processes. Indeed, as our analyses have progressed to consider our full 2-year 'immunodynamics' dataset in the light of infection variables, a key finding has related to the immunological basis of disease tolerance to some infection types in wild field voles (Jackson et al. submitted). Disease tolerance is a defence mechanism whereby the host endures infection whilst minimizing the damage caused by the pathogen itself or by the host's own immune response (Ayres and Schneider, 2012; Medzhitov et al. 2012). This is distinct from disease resistance, where the host actively detects and eliminates pathogens, in that tolerance has no obvious effect on pathogen burden. Although the mechanisms of resistance are well understood, there is still relatively little known about the natural ability of animals to tolerate infection. Studies of natural populations are thus likely to provide a great many insights into this somewhat neglected defence mechanism (Turner and Paterson, 2013).

The results briefly described in this section have begun to identify important processes in hostparasite relationships that result from variation in immune function and were not immediately apparent from a simpler focus on just the parasites and the hosts themselves. In the future, continuing development of immunological methods for $M$. agrestis and the possibility to monitor the expression of many more genes using RNAseq, very high throughput Q-PCR and bioplexing are likely to further extend our understanding of the strategic role of the immune system within life history variation.

GENETICS, SELECTION AND DISEASE SUSCEPTIB I L ITY

It is now well established that genetic diversity underlies a substantial component of the variation 
in susceptibility to infectious disease observed in natural populations. Just as they have for immunological studies, laboratory rodents have proved an invaluable resource in the discovery and functional annotation of genes involved in immunity to infection. However, although these animals are wellestablished functional genetic models, they differ from natural populations-including those of humans - in several important ways. First, laboratory rodents are generally inbred and therefore lack the genetic diversity of natural populations; second, genetic variation between laboratory strains is driven by selective breeding and deliberate mutations of the genome, rather than natural selection and genetic drift in the wild; third, laboratories provide homogeneous, comfortable and largely sterile environments with none of the pressures of the natural environment (for example, suboptimal nutrition, fluctuating climate, predation, competition etc.); and finally, laboratory infection experiments have tended to concentrate on single infections, whereas individuals in the natural environment are likely to experience multiple simultaneous or sequential infections by a taxonomically diverse set of parasites. Because of this lack of ecological validity, functional laboratory studies-while providing numerous mechanistic insights-offer few insights into the causes and consequences of natural genetic diversity, or the role of natural selection in the maintenance of variation in immune function and disease resistance. Wild rodents, in contrast, are related to laboratory rodents already well-established as genetic models and yet provide a much more realistic ecological model of human and other natural populations. They have therefore been put forward as a novel model to utilize and build on the genetic resources gained from their laboratory cousins, thus providing biomedically relevant yet ecologically valid insights into the genetic determinants of immunity and infectious disease susceptibility (Turner and Paterson, 2013).

In an attempt to broaden the immunogenetic research traditionally conducted on laboratory rodents to natural populations, Turner et al. (2011) used the longitudinal and cross-sectional system of Jackson et al. (2011) (see Immunology and Datasets) to examine the genetic diversity within a number of Kielder field vole immune genes.

Turner et al. concentrated primarily on cytokines, signalling molecules that facilitate communication between immune cells and which are crucial in the induction and polarization of immune responses. Despite the breadth of genetic research into cytokines in human and laboratory studies, there have thus far been relatively few studies on wildlife, where the overwhelming majority of immunogenetic studies have concentrated on the major histocompatibility complex (MHC) (Acevedo-Whitehouse and Cunningham, 2006).
The little previous research on the impact of cytokine genetic variation on parasite resistance in natural populations had concentrated on non-coding regions of a single gene, Interferon gamma (Coltman et al. 2001; Ezenwa et al. 2010). In their study, Turner et al. (2011) examined genetic polymorphism within protein-coding regions of a number of immune loci, and its association with individual variation in both immune responses and susceptibility to endemic pathogens. The authors utilized multiple regression methods to first control for confounding non-genetic factors, many of which were identified in the immunodynamics study of Jackson et al. (2011). Turner et al. demonstrated strong associations between genetic polymorphism within three cytokines (Interleukin 1 beta [Il1b], Il2 and $I l 12 b$ ) and individual variation in immune responses, as measured through expression levels of multiple immune genes. Following this, the authors hypothesized that if genetic variation at cytokine loci affects immune responses, it would likely also impact upon susceptibility to pathogens. To test this, Turner et al. again first controlled for possible confounding factors, and subsequently found that the same three genes associated with variation in immune responses-Illb, Il2 and $I l 12 b$-were also strongly associated with variation in susceptibility to a number of endemic micro- and macroparasites. The magnitude of the genetic effects on both immune responses and pathogen resistance were of comparable size to non-genetic factors that are commonly acknowledged as important in natural studies of infection, such as age and sex. Importantly, given the importance of simultaneous infections in the Kielder voles (see Co-infection), all genetic effects remained after addition of co-infecting parasites to the models as explanatory variables. Moreover, the fact that these genes were associated with resistance to a taxonomically diverse range of natural pathogens (bacteria, protozoa, helminths and arthropod ectoparasites) demonstrates the value of examining such genetic relationships in the wild, in contrast to laboratory studies that typically focus on single experimental infections (Turner et al. 2011). For example, pleiotropic and apparently antagonistic effects of genetic variation were noted, with genetic variants simultaneously associated with an increased likelihood of infection with one parasite and a decreased chance of infection by another, a trade-off which has also been noted among different laboratory mouse genotypes (Pedersen and Babayan, 2011). This suggests that the advantage conferred on the host by a 'protective' genotype against one pathogen depends greatly on the context of the local pathogen community.

Understanding how the considerable heterogeneity among individuals in immune function and disease susceptibility is generated and maintained is a central question in evolutionary biology. In a 
complementary study to that above, Turner et al. (2012) therefore examined the role of natural selection in shaping diversity within field vole immune genes. Using a range of population genetic techniques they discovered signatures of natural selection acting on several cytokine and TLR genes. Of particular note was that high levels of genetic diversity observed within $I l 1 b$ and $I l 2$ genes, both of which were strongly associated with variation in immune function and pathogen susceptibility, appear to have been maintained via balancing selection (a term encompassing any type of natural selection which acts to maintain genetic variation). There are several forms of balancing selection (including overdominance and frequency-dependent selection) and disentangling which mechanism(s) are the most important is challenging (Spurgin and Richardson, 2010). However, as pathogen abundances vary spatiotemporally in Kielder Forest (see for example Cavanagh et al. 2004; Telfer et al. 2007a, b), there are likely to be multiple pathogen-specific-and often competing-selection pressures acting concurrently. As such, fluctuating selection for different alleles at different points in space and/or time is the most likely mechanism driving the maintenance of polymorphism at these loci, particularly given the antagonistic and pleiotropic effects of genetic variation observed (Turner et al. 2011, 2012). Integration of the findings of the two studies by Turner et al. therefore provides robust, corroborative evidence that genetic diversity at cytokine loci has a discernible effect on susceptibility to a number of infectious diseases, via cytokinemediated modulation of host immune phenotypes. In turn, as has been commonly reported for genes within the MHC (Piertney and Oliver, 2006; Spurgin and Richardson, 2010), cytokine genetic diversity is then maintained through the action of pathogen-mediated balancing selection (Fig. 5).

\section{CONCLUSIONS}

Studies of infectious diseases in wild rodent populations have traditionally been driven by perhaps two major motivations (Begon, 2003). First, a fundamental desire to understand the ecological importance of the interactions between hosts and their parasites and, second, a more applied goal of understanding the dynamics of rodent reservoirs and their pathogens in order to practice disease control. In the first case, the work at Kielder, and indeed the work on bank voles and wood mice that spawned it, has made important connections between theoretical and conceptual ideals and the realities of the living world. Traditional dogmas and real data have been brought into contact with one another with regard, for example, to transmission functions, crossspecies transmission, apparent competition, co-infection and the place of parasites in the web of a host's interactions more generally. In the second case, while

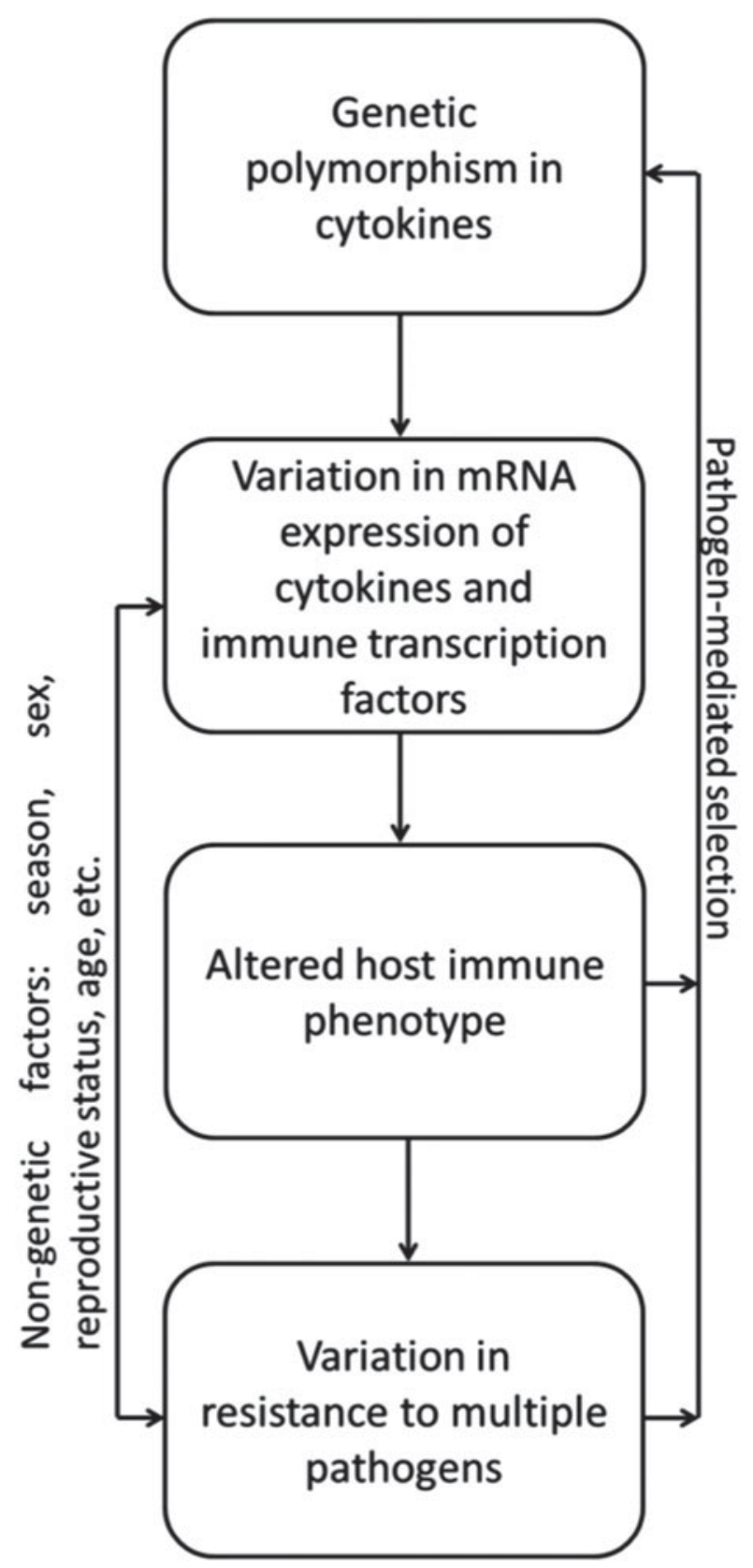

Fig. 5. Causes and consequences of immunogenetic variation in Kielder voles. Polymorphism within cytokine genes - interacting with non-genetic factors - has a discernible effect on the transcription of immune genes and thus on host immune phenotype. Phenotypic variation in immune responses leads to variation among individuals in resistance to a taxonomically diverse range of endemic pathogens, the selective pressures of which drive the maintenance of cytokine genetic diversity. From Turner and Paterson (2013).

many of the focal parasites have been zoonotic in principle, their public health importance in the UK has been limited. Nonetheless, techniques and approaches developed at Kielder have proved their value, and their transferability, when applied elsewhere, most notably perhaps to the plague-gerbil system in Central Asia (e.g. Davis et al. 2004, 2008). 
With the advent of genomic technologies and the continued rise of ecological ('wild') immunology (Sheldon and Verhulst, 1996; Schulenburg et al. 2009; Martin et al. 2011; Pedersen and Babayan, 2011), a further motivation has now emerged: to expand traditional genetic and immunological research beyond laboratory models and into the natural world. There is an increasing recognition that fields that developed in relative isolation, such as molecular biology, ecology, immunology, epidemiology and evolutionary biology are not as distinct as they once appeared (Schmid-Hempel, 2011). Adopting an integrative approach to research, utilizing knowledge and resources from several fields, presents an excellent opportunity to bridge the gap between laboratory studies and the natural world and to better understand the nature of host-parasite interactions on many levels. We hope that the long-term, multidisciplinary research on the Kielder field voles and other natural systems will continue to provide fresh insights relevant not only to evolutionary biology and ecology, but also to conservation biology and biomedical science.

\section{ACKNOWLEDGEMENTS}

We are pleased to acknowledge the contributions of all those who have been involved in the work reviewed here. Even those who have been co-authors on the relevant papers would be too numerous to mention, and there are many more. Special mention must be made, though, of Sandra Telfer whose particular contribution has been immense. We are most grateful, too, to NERC and The Wellcome Trust for their financial support.

\section{REFERENCES}

Acevedo-Whitehouse, K. and Cunningham, A. A. (2006). Is MHC enough for understanding wildlife immunogenetics? Trends in Ecology and Evolution 21, 433-438. doi: 10.1016/j.tree.2006.05.010.

Albright, J. W. and Albright, J. F. (1991). Rodent trypanosomes: their conflict with the immune system of the host. Parasitology Today 7, 137-140. Anderson, R. M. and May, R. M. (1979). Population biology of infectious diseases: part I. Nature 280, 361-367. doi: 10.1038/280361a0.

Arthur, D. R. (1963). British Ticks. Butterworths, London, UK.

Ayres, J. S. and Schneider, D. S. (2012). Tolerance of infections. Annual Review of Immunology 30, 271-294. doi: 10.1146/annurev-immunol020711-075030.

Baxby, D. and Bennett, M. (1999). Cowpox virus (Poxviridae). In Encyclopedia of Virology (ed. Webster, R. G. and Granhoff, A.), pp. 298-304. Academic Press, London, UK.

Baxby, D., Bennett, M. and Getty, B. (1994). Human cowpox 1969-93: a review based on 54 cases. British Fournal of Dermatology 131, 598-607.

Begon, M. (2003). Disease: health effects on humans, population effects on rodents. In Rats, Mice and People: Rodent Biology and Management (ed. Singleton, G. R., Hinds, L. A., Krebs, C. J. and Spratt, D. M.), pp. 13-19. Australian Centre for International Agricultural Research, Canberra, Australia.

Begon, M. (2008). Effects of host diversity on disease dynamics. In Infectious Disease Ecology: Effects of Ecosystems on Disease and of Disease on Ecosystems (ed. Ostfeld, R. S., Keesing, F. and Eviner, V. T.), pp. 12-29. Princeton University Press, Princeton, NJ, USA.

Begon, M. and Bowers, R. G. (1994). Host-host-pathogen models and microbial pest control: the effect of host self regulation. Fournal of Theoretical Biology 169, 275-287.

Begon, M., Sait, S. M. and Thompson, D. J. (1996). Predator-prey cycles with period shifts between two-and three-species systems. Nature 381, 311-315. doi: 10.1038/381311a0.
Begon, M., Feore, S. M., Bown, K., Chantrey, J., Jones, T. and Bennett, M. (1998). Population and transmission dynamics of cowpox in bank voles: testing fundamental assumptions. Ecology Letters 1, 82-86.

Begon, M., Hazel, S. M., Baxby, D., Bown, K., Cavanagh, R., Chantrey, J., Jones, T. and Bennett, M. (1999). Transmission dynamics of a zoonotic pathogen within and between wildlife host species. Proceedings of the Royal Society B: Biological Sciences 266, 1939-1945.

Begon, M., Hazel, S.M., Telfer, S., Bown, K., Carslake, D., Cavanagh, R., Chantrey, J., Jones, T. and Bennett, M. (2003). Rodents, cowpox virus and islands: densities, numbers and thresholds. Fournal of Animal Ecology 72, 343-355. doi: 10.1046/j.13652656.2003.00705.x.

Begon, M., Telfer, S., Burthe, S., Lambin, X., Smith, M. J. and Paterson, S. $(2009 a)$. Effects of abundance on infection in natural populations: field voles and cowpox virus. Epidemics 1, 35-46. doi: 10.1016/j.epidem.2008.10.001.

Begon, M., Telfer, S., Smith, M.J., Burthe, S., Paterson, S. and Lambin, X. (2009b). Seasonal host dynamics drive the timing of recurrent epidemics in a wildlife population. Proceedings of the Royal Society B: Biological Sciences 276, 1603-1610. doi: 10.1098/rspb.2008.1732.

Beldomenico, P. M. and Begon, M. (2010). Disease spread, susceptibility and infection intensity: vicious circles? Trends in Ecology and Evolution 25, 21-27. doi: 10.1016/j.tree.2009.06.015.

Beldomenico, P. M., Telfer, S., Gebert, S., Lukomski, L., Bennett, M. and Begon, M. (2008a). Poor condition and infection: a vicious circle in natural populations. Proceedings of the Royal Society of London B: Biological Sciences 275, 1753-1759. doi: 10.1098/rspb.2008.0147.

Beldomenico, P. M., Telfer, S., Gebert, S., Lukomski, L., Bennett, M. and Begon, M. (2008b). The dynamics of health in wild field vole populations: a haematological perspective. Fournal of Animal Ecology 77, 984-997. doi: 10.1111/j.1365-2656.2008.01413.x.

Beldomenico, P. M., Telfer, S., Gebert, S., Lukomski, L., Bennett, M. and Begon, M. (2008c). Azurocytes in wild field voles: factors associated with their occurrence. EcoHealth 5, 317-327. doi: 10.1007/s10393-0080186-9.

Beldomenico, P.M., Telfer, S., Lukomski, L., Gebert, S. and Bennett, M. (2009a). Host condition and individual risk of cowpox virus infection in natural animal populations: cause or effect? Epidemiology and Infection 137, 1295-1301. doi: 10.1017/S0950268808001866.Host.

Beldomenico, P. M., Telfer, S., Gebert, S., Lukomski, L., Bennett, M. and Begon, M. (2009b). The vicious circle and infection intensity: the case of Trypanosoma microti in field vole populations. Epidemics 1, 162-167. doi: 10.1016/j.epidem.2009.05.002.

Bierman, S. M., Fairbairn, J. P., Petty, S. J., Elston, D. A., Tidhar, D. and Lambin, X. (2006). Changes over time in the spatiotemporal dynamics of cyclic populations of field voles (Microtus agrestis L.). American Naturalist 167, 583-590. doi: 10.1086/501076.

Birtles, R. J. (2005). Bartonellosis. In Arthropod-borne Infectious Diseases of the Dog and Cat (ed. Shaw, S. E. and Day, M. J.), pp. 110-119. CRC Press, London, UK.

Birtles, R. J., Harrison, T. G. and Molyneux, D. H. (1994). Grahamella in small woodland mammals in the U.K.: isolation, prevalence and host specificity. Annals of Tropical Medicine and Parasitology 88, 317-327.

Birtles, R. J., Hazel, S. M., Bennett, M., Bown, K., Raoult, D. and Begon, M. (2001). Longitudinal monitoring of the dynamics of infections due to Bartonella species in UK woodland rodents. Epidemiology and Infection 126, 323-329.

Blanchet, S., Méjean, L., Bourque, J.-F., Lek, S., Thomas, F., Marcogliese, D. J., Dodson, J. J. and Loot, G. (2009). Why do parasitized hosts look different? Resolving the "chicken-egg" dilemma. Oecologia 160, 37-47. doi: 10.1007/s00442-008-1272-y.

Boonstra, R. and Krebs, C. (1979). Viability of large- and small-sized adults in fluctuating vole populations. Ecology 60, 567-573.

Bown, K. J., Begon, M., Bennett, M., Woldehiwet, Z. and Ogden, N. H. (2003). Seasonal dynamics of Anaplasma phagocytophila in a rodent-tick (Ixodes trianguliceps) system, United Kingdom. Emerging Infectious Diseases 9, 63-70. doi: 10.3201/eid0901.020169.

Bown, K. J., Begon, M., Bennett, M., Birtles, R. J., Burthe, S., Lambin, X., Telfer, S., Woldehiwet, Z. and Ogden, N. H. (2006). Sympatric Ixodes trianguliceps and Ixodes ricinus ticks feeding on field voles (Microtus agrestis): potential for increased risk of Anaplasma phagocytophilum in the United Kingdom? Vector Borne and Zoonotic Diseases 6, 404-410. doi: 10.1089/vbz.2006.6.404.

Bown, K. J., Lambin, X., Telford, G. R., Ogden, N.H., Telfer, S., Woldehiwet, Z. and Birtles, R. J. (2008). Relative importance of Ixodes ricinus and Ixodes trianguliceps as vectors for Anaplasma phagocytophilum and Babesia microti in field vole (Microtus agrestis) populations. 
Applied and Environmental Microbiology 74, 7118-7125. doi: 10.1128/ AEM.00625-08.

Bown, K. J., Lambin, X., Ogden, N.H., Begon, M., Telford, G., Woldehiwet, Z. and Birtles, R. J. (2009). Delineating Anaplasma phagocytophilum ecotypes in coexisting, discrete enzootic cycles. Emerging Infectious Diseases 15, 1948-1954. doi: 10.3201/eid1512.090178.

Bown, K. J., Lambin, X., Telford, G., Heyder-Bruckner, D., Ogden, N. H. and Birtles, R. J. (2011). The common shrew (Sorex araneus): a neglected host of tick-borne infections? Vector Borne and Zoonotic Diseases 11, 947-953. doi: 10.1089/vbz.2010.0185.

Bradley, J. E. and Jackson, J. A. (2008). Measuring immune system variation to help understand host-pathogen community dynamics. Parasitology 135, 807-823. doi: 10.1017/S0031182008000322.

Buffet, J.-P., Kosoy, M. and Vayssier-Taussat, M. (2013). Natural history of Bartonella infecting rodents in light of new knowledge on genomics, diversity and evolution. Future Microbiology 8, 1117-1128. doi: 10.2217/fmb.13.77

Burthe, S., Telfer, S., Lambin, X., Bennett, M., Carslake, D., Smith, A. and Begon, M. (2006). Cowpox virus infection in natural field vole Microtus agrestis populations: delayed density dependence and individual risk. Fournal of Animal Ecology 75, 1416-1425. doi: 10.1111/j.13652656.2006.01166.x.

Burthe, S., Telfer, S., Begon, M., Bennett, M., Smith, A. and Lambin, X. (2008a). Cowpox virus infection in natural field vole Microtus agrestis populations: significant negative impacts on survival. Fournal of Animal Ecology 77, 110-119. doi: 10.1111/j.13652656.2007.01302.x.

Burthe, S., Bennett, M., Kipar, A., Lambin, X., Smith, A., Telfer, S. and Begon, M. (2008b). Tuberculosis (Mycobacterium microti) in wild field vole populations. Parasitology 135, 309-317. doi: 10.1017/ S0031182007003940.

Burthe, S. J., Lambin, X., Telfer, S., Douglas, A., Beldomenico, P., Smith, A. and Begon, M. (2010). Individual growth rates in natural field vole, Microtus agrestis, populations exhibiting cyclic population dynamics. Oecologia 162, 653-661. doi: 10.1007/s00442-009-1495-6.

Carslake, D., Bennett, M., Bown, K., Hazel, S., Telfer, S. and Begon, M. (2005). Space-time clustering of cowpox virus infection in wild rodent populations. Fournal of Animal Ecology 74, 647-655.

Carslake, D., Bennett, M., Hazel, S., Telfer, S. and Begon, M. (2006). Inference of cowpox virus transmission rates between wild rodent host classes using space-time interaction. Proceedings of the Royal Society B: Biological Sciences 273, 775-782.

Cavanagh, R., Begon, M., Bennett, M., Ergon, T., Graham, I. M., de Haas, P., Hart, C., Koedam, M., Kremer, K., Lambin, X., Roholl, P. and van Soolingen, D. (2002). Mycobacterium microti infection (vole tuberculosis) in wild rodent populations. Fournal of Clinical Microbiology 40, 3281-3285. doi: 10.1128/JCM.40.9.3281

Cavanagh, R. D., Lambin, X., Ergon, T., Bennett, M., Graham, I. M., van Soolingen, D. and Begon, M. (2004). Disease dynamics in cyclic populations of field voles (Microtus agrestis): cowpox virus and vole tuberculosis (Mycobacterium microti). Proceedings of the Royal Society B: Biological Sciences 271, 859-867. doi: 10.1098/rspb.2003.2667.

Chantrey, J., Meyer, H., Baxby, D., Begon, M., Bown, K. J., Hazel, S. M., Jones, T., Montgomery, W. I. and Bennett, M. (1999). Cowpox: reservoir hosts and geographic range. Epidemiology and Infection 122, 455-460.

Chen, S. M., Dumler, J. S., Bakken, J. S. and Walker, D. H. (1994). Identification of a granulocytotropic Ehrlichia species as the etiologic agent of human disease. Fournal of Clinical Microbiology 32, 589-595.

Chitty, D. (1952). Mortality among voles (Microtus agrestis) at Lake Vyrnwy, Montgomeryshire, in 1936-9. Philosophical Transactions of the Royal Society of London B: Biological Sciences 236, 505-552.

Chitty, D. (1954). Tuberculosis among wild voles: with a discussion of other pathological conditions among certain mammals and birds. Ecology 35, 227-237.

Chitty, D. (1996). Do Lemmings Commit Suicide? Beautiful Hypotheses and Ugly Facts. Oxford University Press, New York, NY, USA.

Clutton-Brock, T. H. and Pemberton, J. M. (eds.) (2004). Soay Sheep: Dynamics and Selection in an Island Population. Cambridge University Press, Cambridge, UK.

Coltman, D. W., Wilson, K., Pilkington, J. G., Stear, M. J. and Pemberton, J. M. (2001). A microsatellite polymorphism in the gamma interferon gene is associated with resistance to gastrointestinal nematodes in a naturally-parasitized population of Soay sheep. Parasitology 122, 571-582.

Crouch, A. C., Baxby, D., McCracken, C. M., Gaskell, R. M. and Bennett, M. (1995). Serological evidence for the reservoir hosts of cowpox virus in British wildlife. Epidemiology and Infection 115, 185-191.
Davis, S., Begon, M., De Bruyn, L., Ageyev, V. S., Klassovskiy, N. L., Pole, S. B., Viljugrein, H., Stenseth, N. C. and Leirs, H. (2004). Predictive thresholds for plague in Kazakhstan. Science 304, 736-738. doi 10.1126/science.1095854

Davis, S., Trapman, P., Leirs, H., Begon, M. and Heesterbeek, J. A. P. (2008). The abundance threshold for plague as a critical percolation phenomenon. Nature 454, 634-637. doi: 10.1038/nature07053.

Demas, G. E., Zysling, D. A., Beechler, B. R., Muehlenbein, M. P. and French, S. S. (2011). Beyond phytohaemagglutinin: assessing vertebrate immune function across ecological contexts. Fournal of Animal Ecology 80 , 710-730. doi: 10.1111/j.1365-2656.2011.01813.x.

Dye, C. and Williams, B. G. (1995). Nonlinearities in the dynamics of indirectly transmitted infections (or, does having a vector make a difference?). In Ecology of Infectious Diseases in Natural Populations (ed. Grenfell, B. T. and Dobson, A. P.), pp. 260-279. Cambridge University Press, Cambridge, UK.

Elton, C. S. (1924). Periodic fluctuations in the numbers of animals: their causes and effects. Forunal of Experimental Biology 2, 119-163.

Elton, C. S. (1942). Voles, Mice and Lemmings. Clarendon Press, Oxford, UK

Elton, C. S., Ford, E. B., Baker, J. R. and Gardner, A. D. (1931). The health and parasites of a wild mouse population. Proceedings of the Zoological Society of London 101, 657-721.

Elton, C. S., Davis, D. H. S. and Findlay, G. M. (1935). An epidemic among voles (Microtus agrestis) on the Scottish Border in the spring of 1934 Fournal of Animal Ecology 4, 277-288.

Emmanuel, F. X., Seagar, A.-L., Doig, C., Rayner, A., Claxton, P. and Laurenson, I. (2007). Human and animal infections with Mycobacterium microti, Scotland. Emerging Infectious Diseases 13, 1924-1927.

Ergon, T., Lambin, X. and Stenseth, N. (2001a). Life-history traits of voles in a fluctuating population respond to the immediate environment. Nature 411, 1043-1045.

Ergon, T., MacKinnon, J. L., Stenseth, N. C., Boonstra, R. and Lambin, X. (2001b). Mechanisms for delayed density-dependent reproductive traits in field voles, Microtus agrestis: the importance of inherited environmental effects. Oikos 95, 185-197.

Ergon, T., Ergon, R., Begon, M., Telfer, S. and Lambin, X. (2011) Delayed density-dependent onset of spring reproduction in a fluctuating population of field voles. Oikos 120, 934-940. doi: 10.1111/j.16000706.2010.18983.x.

Ezenwa, V. O., Etienne, R.S., Luikart, G., Beja-Pereira, A. and Jolles, A. E. (2010). Hidden consequences of living in a wormy world: nematode-induced immune suppression facilitates tuberculosis invasion in African buffalo. American Naturalist 176, 613-624. doi: $10.1086 / 656496$

Feldman, B. F., Zink1, J. G. and Jain, N.C. (2000). Schalm's Veterinary Hematology. Lippincott Williams \& Wilkins, Philadelphia, PA, USA.

Feore, S. M., Bennett, M., Chantrey, J., Jones, T., Baxby, D. and Begon, M. (1997). The effect of cowpox virus infection on fecundity in bank voles and wood mice. Proceedings of the Royal Society B: Biological Sciences 264, 1457-1461. doi: 10.1098/rspb.1997.0202.

Foggie, A. (1949). Studies on tick-borne fever in sheep. Fournal of General Microbiology 3, v-vi.

Graham, I. M. and Lambin, X. (2002). The impact of weasel predation on cyclic field-vole survival: the specialist predator hypothesis contradicted. Fournal of Animal Ecology 71, 946-956. doi: 10.1046/j.13652656.2002.00657.x

Hazel, S. M., Bennett, M., Chantrey, J., Bown, K., Cavanagh, R., Jones, T. R., Baxby, D. and Begon, M. (2000). A longitudinal study of an endemic disease in its wildlife reservoir: cowpox and wild rodents. Epidemiology and Infection 124, 551-562.

Hudson, J. R. (1950). The recognition off tick-borne fever as a disease of cattle. British Veterinary fournal 106, 3-17.

Huitu, O., Jokinen, I., Korpimäki, E., Koskela, E. and Mappes, T. (2007). Phase dependence in winter physiological condition of cyclic voles. Oikos 116, 565-577. doi: 10.1111/j.2007.0030-1299.15488.x

Jackson, J. A., Pleass, R. J., Cable, J., Bradley, J. E. and Tinsley, R. C. (2006). Heterogeneous interspecific interactions in a host-parasite system. International Fournal for Parasitology 36, 1341-1349. doi: 10.1016/j. ijpara.2006.07.003.

Jackson, J. A., Friberg, I. M., Bolch, L., Lowe, A., Ralli, C., Harris, P.D., Behnke, J. M. and Bradley, J.E. (2009). Immunomodulatory parasites and Toll-like receptor-mediated tumour necrosis factor alpha responsiveness in wild mammals. BMC Biology 7, 16. doi: 10.1186/1741-7007-7-16.

Jackson, J. A., Begon, M., Birtles, R., Paterson, S., Friberg, I. M., Hall, A., Lowe, A., Ralli, C., Turner, A., Zawadzka, M. and 
Bradley, J.E. (2011). The analysis of immunological profiles in wild animals: a case study on immunodynamics in the field vole, Microtus agrestis. Molecular Ecology 20, 893-909. doi: 10.1111/j.1365-294X. 2010.04907.x.

Kipar, A., Burthe, S. J., Hetzel, U., Rokia, M. A., Telfer, S., Lambin, X., Birtles, R. J., Begon, M. and Bennett, M. (2013) Mycobacterium microti tuberculosis in its maintenance host, the field vole (Microtus agrestis): characterization of the disease and possible routes of transmission. Veterinary Pathology [Epub ahead of print]. doi: 10.1177/ 0300985813513040 .

Kosoy, M. Y., Regnery, R. L., Tzianabos, T., Marston, E. L., Jones, D. C., Green, D., Maupin, G. O., Olson, J. G. and Childs, J. E. (1997). Distribution, diversity, and host specificity of Bartonella in rodents from the Southeastern United States. American fournal of Tropical Medicine and Hygiene 57, 578-588

Lambin, X., Elston, D. A., Petty, S. J. and MacKinnon, J. L. (1998). Spatial asynchrony and periodic travelling waves in cyclic populations of field voles. Proceedings of the Royal Society B: Biological Sciences 265, 1491-1496. doi: 10.1098/rspb.1998.0462.

Lambin, X., Petty, S. J. and Mackinnon, J. L. (2000). Cyclic dynamics in field vole populations and generalist predation. Fournal of Animal Ecology 69, 106-119. doi: 10.1046/j.1365-2656.2000.00380.x.

Lochmiller, R. (1996). Immunocompetence and animal population regulation. Oikos 76, 594-602.

Lochmiller, R. L. and Deerenberg, C. (2000). Trade-offs in evolutionary immunology: just what is the cost of immunity? Oikos 88, 87-98. doi: 10.1034/j.1600-0706.2000.880110.x.

Mackinnon, J. L., Petty, S. J., Elston, D. A., Thomas, C. J., Sherratt, T. N. and Lambin, X. (2001). Scale invariant spatio-tempora patterns of field vole density. Fournal of Animal Ecology 70, 101-111. doi: 10.1111/j.1365-2656.2001.00479.x.

Martin, L. B., Hawley, D. M. and Ardia, D. R. (2011). An introduction to ecological immunology. Functional Ecology 25, 1-4. doi: 10.1111/j.13652435.2010.01820.x

Massung, R. F., Priestley, R.A., Miller, N. J., Mather, T. N. and Levin, M. L. (2003). Inability of a variant strain of Anaplasma phagocytophilum to infect mice. Fournal of Infectious Diseases 188, 1757-1763. doi: $10.1086 / 379725$.

May, R. M. and Anderson, R. M. (1979). Population biology of infectious diseases: part II. Nature 280, 455-461. doi: 10.1038/280455a0.

Medzhitov, R., Schneider, D.S. and Soares, M.P. (2012) Disease tolerance as a defense strategy. Science 335, 936-941. doi: $10.1126 /$ science. 1214935 .

Mihok, S. and Schwartz, B. (1991). Artificial induction of azurocytes in the meadow vole (Microtus pennsylvanicus). Comparative Biochemistry and Physiology Part C: Comparative Pharmacology 99, 213-218. doi: 10.1016/ 0742-8413(91)90102-Y.

Mihok, S., Descoteaux, J.-P., Lawton, T., Lobreau, A. and Schwartz, B. (1987). The azurocyte: a new kind of leukocyte from wild voles (Microtus). Canadian Fournal of Zoology 65, 54-62.

Morick, D., Krasnov, B. R., Khokhlova, I. S., Gutiérrez, R. Gottlieb, Y. and Harrus, S. (2013). Vertical nontransovarial transmission of Bartonella in fleas. Molecular Ecology 22, 4747-4752. doi: 10.1111/ mec.12408.

Myllymaki, A., Paasikallio, A., Pankakoski, E. and Kanervo, V. (1971). Removal experiments on small quadrats as a means of rapid assessment of the abundance of small mammals. Annales Zoologici Fennici 8 , $177-185$.

Niemann, S., Richter, E., Dalügge-Tamm, H., Schlesinger, H., Graupner, D., Königstein, B., Gurath, G., Greinert, U. and Rüsch-Gerdes, S. (2000). Two cases of Mycobacterium microti derived tuberculosis in HIV-negative immunocompetent patients. Emerging Infectious Diseases 6, 539-542. doi: 10.3201/eid0605.000516.

Norman, R., Bowers, R. G., Begon, M. and Hudson, P. J. (1999). Persistence of tick-borne virus in the presence of multiple host species: tick reservoirs and parasite mediated competition. Fournal of Theoretical Biology 200, 111-118

Noyes, H. A., Ambrose, P., Barker, F., Begon, M., Bennet, M. Bown, K. J. and Kemp, S. J. (2002). Host specificity of Trypanosoma (Herpetosoma) species: evidence that bank voles (Clethrionomys glareolus) carry only one $T$. $(H$.) evotomys $18 \mathrm{~S}$ rRNA genotype but wood mice (Apodemus sylvaticus) carry at least two polyphyletic parasites. Parasitology 124, 185-190.

Paun, A., Reinert, J. T., Jiang, Z., Medin, C., Balkhi, M. Y., Fitzgerald, K. A. and Pitha, P. M. (2008). Functional characterization of murine interferon regulatory factor 5 (IRF-5) and its role in the innate antiviral response. Fournal of Biological Chemistry 283, 14295-14308. doi: 10.1074/jbc. M800501200.
Pedersen, A. B. and Babayan, S. A. (2011). Wild immunology. Molecular Ecology 20, 872-880. doi: 10.1111/j.1365-294X.2010.04938.x.

Pedersen, A. B. and Greives, T. J. (2008). The interaction of parasites and resources cause crashes in a wild mouse population. Fournal of Animal Ecology 77, 370-377. doi: 10.1111/j.1365-2656.2007.01321.x.

Petty, S. J. (1992). Ecology of the tawny owl Strix aluco in the spruce forests of Northumberland and Argyll. PhD thesis. Open University, Milton Keynes.

Petty, S. J., Lambin, X., Sherratt, T. N., Thomas, C. J., Mackinnon, J.L., Coles, C. F., Davison, M. and Little, B. (2000). Spatial synchrony in field vole Microtus agrestis abundance in a coniferous forest in northern England: the role of vole-eating raptors. Fournal of Applied Ecology 37, 136-147. doi: 10.1046/j.1365-2664.2000.00473.x.

Piertney, S. B. and Oliver, M. K. (2006). The evolutionary ecology of the major histocompatibility complex. Heredity 96, 7-21. doi: 10.1038/sj. hdy. 6800724 .

Pusenius, J. and Viitala, J. (1993). Varying spacing behaviour of breeding field voles, Microtus agrestis. Annales Zoologici Fennici 30, 143-152.

Randolph, S. E. (1975). Patterns of distribution of the tick Ixodes trianguliceps Birula on its hosts. Fournal of Animal Ecology 44, 451-474.

Randolph, S.E. (1991). The effect of Babesia microti on feeding and survival in its tick vector, Ixodes trianguliceps. Parasitology 102, 9-16.

Randolph, S. E. (1995). Quantifying parameters in the transmission of Babesia microti by the tick Ixodes trianguliceps amongst voles (Clethrionomys glareolus). Parasitology 110, 287-295.

Randolph, S. E. and Dobson, A. D. M. (2012). Pangloss revisited: a critique of the dilution effect and the biodiversity-buffers-disease paradigm. Parasitology 139, 847-863.

Reiner, S. L. (2007). Development in motion: helper T cells at work. Cell 129, 33-36. doi: 10.1016/j.cell.2007.03.019.

Schmid-Hempel, P. (2011). Evolutionary Parasitology: the Integrated Study of Infections, Immunology, Ecology, and Genetics. Oxford University Press, Oxford, UK.

Schulenburg, H., Kurtz, J., Moret, Y. and Siva-Jothy, M. T. (2009). Introduction. Ecological immunology. Philosophical Transactions of the Royal Society of London B: Biological Sciences 364, 3-14. doi: 10.1098/ rstb.2008.0249.

Seet, B. T., Johnston, J. B., Brunetti, C. R., Barrett, J. W., Everett, H., Cameron, C., Sypula, J., Nazarian, S. H., Lucas, A. and McFadden, G. (2003). Poxviruses and immune evasion. Annual Review of Immunology 21, 377-423. doi: 10.1146/annurev.immunol.21.120601.141049.

Sheldon, B. C. and Verhulst, S. (1996). Ecological immunology: costly parasite defences and trade-offs in evolutionary ecology. Trends in Ecology and Evolution 11, 317-321

Sherlock, C., Xifara, T., Telfer, S. and Begon, M. (2013). A coupled hidden Markov model for disease interactions. Fournal of the Royal Statistical Society: Series C (Applied Statistics) 62, 609-627.

Sherratt, J.A. (2001). Periodic travelling waves in cyclic predatorprey systems. Ecology Letters 4, 30-37. doi: 10.1046/j.1461-0248. 2001.00193.x.

Smith, A., Telfer, S., Burthe, S., Bennett, M. and Begon, M. (2005) Trypanosomes, fleas and field voles: ecological dynamics of a host-vectorparasite interaction. Parasitology 131, 355. doi: 10.1017 S0031182005007766.

Smith, A., Telfer, S., Burthe, S., Bennett, M. and Begon, M. (2006). A role for vector-independent transmission in rodent trypanosome infection? International Fournal for Parasitology 36, 1359-1366. doi: 10.1016/j. ijpara.2006.06.014.

Smith, M. J., White, A., Sherratt, J. A., Telfer, S., Begon, M. and Lambin, X. (2008). Disease effects on reproduction can cause population cycles in seasonal environments. Fournal of Animal Ecology 77, 378-389. doi: 10.1111/j.1365-2656.2007.01328.x.

Smith, M. J., Telfer, S., Kallio, E. R., Burthe, S., Cook, A. R., Lambin, X. and Begon, M. (2009). Host-pathogen time series data in wildlife support a transmission function between density and frequency dependence. Proceedings of the National Academy of Sciences USA 106 7905-7909.

Snow, K. R. (1979). Identification of Larval Ticks Found on Small Mammals in Britain. The Mammal Society, Reading.

Spurgin, L. G. and Richardson, D.S. (2010). How pathogens drive genetic diversity: MHC, mechanisms and misunderstandings. Proceedings of the Royal Society B: Biological Sciences 277, 979-988. doi: 10.1098/ rspb.2009.2084

Stockham, S. and Scott, M. (2002). Fundamentals of Veterinary Clinical Pathology. Iowa State Press, Ames, IA, USA.

Stone, L., Olinky, R. and Huppert, A. (2007). Seasonal dynamics of recurrent epidemics. Nature 446, 533-536. doi: 10.1038/nature05638. 
Telfer, S., Bennett, M., Bown, K., Cavanagh, R., Crespin, L., Hazel, S., Jones, T. and Begon, M. (2002). The effects of cowpox virus on survival in natural rodent populations: increases and decreases. Fournal of Animal Ecology 71, 558-568.

Telfer, S., Bown, K., Sekules, R., Begon, M., Hayden, T. and Birtles, R. $(2005 a)$. Disruption of a host-parasite system following the introduction of an exotic host species. Parasitology 130, 661-668.

Telfer, S., Bennett, M., Bown, K., Carslake, D., Cavanagh, R. D. Hazel, S. M., Jones, T. and Begon, M. (2005b). Infection with cowpox virus decreases female maturation rates in wild populations of woodland rodents. Oikos 109, 317-322.

Telfer, S., Begon, M., Bennett, M., Bown, K. J., Burthe, S., Lambin, X., Telford, G. and Birtles, R. (2007a). Contrasting dynamics of Bartonella spp. in cyclic field vole populations: the impact of vector and host dynamics. Parasitology 134, 413-425. doi: 10.1017/ S0031182006001624.

Telfer, S., Clough, H. E., Birtles, L. R. J., Bennett, M., Carslake, D., Helyar, S. and Begon, M. (2007b). Ecological differences and coexistence in a guild of microparasites: Bartonella in wild rodents. Ecology 88, 1841-1849.

Telfer, S., Birtles, R., Bennett, M., Lambin, X., Paterson, S. and Begon, M. (2008). Parasite interactions in natural populations: insights from longitudinal data. Parasitology 135, 767-781. doi: 10.1017/ S0031182008000395.

Telfer, S., Lambin, X., Birtles, R., Beldomenico, P., Burthe, S., Paterson, S. and Begon, M. (2010). Species interactions in a parasite community drive infection risk in a wildlife population. Science 330, 243-246. doi: 10.1126/science.1190333.
Tizard, I. R. (2004). Veterinary Immunology. An Introduction. Saunders, Philadelphia, PA, USA.

Turner, A. K. and Paterson, S. (2013). Wild rodents as a model to discover genes and pathways underlying natural variation in infectious disease susceptibility. Parasite Immunology 35, 386-395.

Turner, A.K., Begon, M., Jackson, J. A., Bradley, J. E. and Paterson, S. (2011). Genetic diversity in cytokines associated with immune variation and resistance to multiple pathogens in a natura rodent population. PLOS Genetics 7, e1002343. doi: 10.1371/journal. pgen.1002343

Turner, A. K., Begon, M., Jackson, J. and Paterson, S. (2012). Evidence for selection at cytokine loci in a natural population of field voles (Microtus agrestis). Molecular Ecology 21, 1632-1646.

Van Soolingen, D., van der Zanden, A. G., de Haas, P. E., Noordhoek, G. T., Kiers, A., Foudraine, N. A., Portaels, F., Kolk, A. H., Kremer, K. and van Embden, J. D. (1998). Diagnosis of Mycobacterium microti infections among humans by using novel genetic markers. Fournal of Clinical Microbiology 36, 1840-1845.

Wells, A. Q. (1946). The Murine Type of Tubercle Bacillus: the Vole Acidfast Bacillus. By A.Q. Wells. With notes on the morphology of infection by the vole acid-fast bacillus by A. H. T. Robb-Smith. Medical Research Council, London, UK.

Wiger, R. (1977). Some pathological effects of endoparasites on rodents with special reference to the population ecology of microtines. Oikos 29, 598-606.

Woldehiwet, Z. (2010). The natural history of Anaplasma phagocytophilum. Veterinary Parasitology 167, 108-122. doi: 10.1016/j. vetpar.2009.09.013. 